\title{
A theory of openness for software engineering tools in software organizations
}

\author{
Hussan Munir ${ }^{*, a}$, Per Runeson ${ }^{\mathrm{a}}$, Krzysztof Wnuk ${ }^{\mathrm{b}}$ \\ ${ }^{a}$ Department of Computer Science, Lund University, P.O. Box 118, SE-221 00 Lund, Sweden \\ ${ }^{\mathrm{b}}$ Software Engineering Research Lab, Blekinge Institute of Technology, SE-371 79 Karlskrona, Sweden
}

\section{A R T I C L E I N F O}

\section{Keywords:}

Open Innovation

Open Source Software

OSS tools

Openness

Theory creation

\begin{abstract}
A B S T R A C T
Context: The increased use of Open Source Software (OSS) affects how software-intensive product development organizations (SIPDO) innovate and compete, moving them towards Open Innovation (OI). Specifically, software engineering tools have the potential for OI, but require better understanding regarding what to develop internally and what to acquire from outside the organization, and how to cooperate with potential competitors. Aim: This paper aims at synthesizing a theory of openness for software engineering tools in SIPDOs, that can be utilized by managers in defining more efficient strategies towards OSS communities.

Method: We synthesize empirical evidence from a systematic mapping study, a case study, and a survey, using a narrative method. The synthesis method entails four steps: (1) Developing a preliminary synthesis, (2) Exploring the relationship between studies, (3) Assessing the validity of the synthesis, and (4) Theory formation. Result: We present a theory of openness for OSS tools in software engineering in relation to four constructs: (1) Strategy, (2) Triggers, (3) Outcomes, and (4) Level of openness.

Conclusion: The theory reasons that openness provides opportunities to reduce the development cost and development time. Furthermore, OI positively impacts on the process and product innovation, but it requires investment by organizations in OSS communities. By betting on openness, organizations may be able to significantly increase their competitiveness.
\end{abstract}

\section{Introduction}

The introduction of Open Source Software (OSS) in commercial settings have opened new possibilities for innovation in software-intensive product development organizations (SIPDOs). ${ }^{1}$ This shift implies that the internal research and development (R\&D) is no longer the only strategic asset for the companies in creating products and services. Access to, and interplay with, external sources and actors provide new opportunities but also create new challenges.

One specific type of OSS is software engineering tools used in the development of software-intensive products. The tools themselves are not the core business of the SIPDOs, but they rely heavily on them to be efficient in their software development. Further, the costs of improving the tools and keeping them up to date may be significant, and thus SIPDOs may want to share the costs with other organizations.

In 2003, Chesbrough proposed the term Open Innovation (OI), later defined as "a distributed innovation process based on purposively managed knowledge flows across organizational boundaries, using pecuniary and nonpecuniary mechanisms in line with the organization's business model" [8].
Cheshbrough's definition of openness hints at valuable ideas that can emerge and commercialize from inside and outside the organization. OI entails various activities, e.g., inbound (also called inside-out), outbound (also called outside-in) and coupled activities [23], and each of these activities can be more or less open. Dahlander and Gann [12] defined inbound versus outbound OI, and pecuniary versus non-pecuniary interactions. Researchers have used the term inside-out/outbound and outside-in/inbound synonymously in the OI literature. The terms used in this paper are defined in Table 1.

This paper uses the openness classification by Huizingh [27] who categorized processes and outcomes as closed or open, see Table 2. Open processes deal with either using the input from outside the organizations, or by externally exploiting an internally developed innovation. This is in contrast to closed processes, where the innovation process is kept in-house [27]. On the other hand, open outcomes entail devoting the scarce resources to innovation, and then giving away the outcome (e.g., proprietary solutions) for free to OSS communities, in contrast to closed outcomes where organizations keep their solution inhouse.

\footnotetext{
* Corresponding author.

E-mail addresses: hussan.munir@cs.1th.se (H. Munir),per.runeson@cs.lth.se (P. Runeson), krzysztof.wnuk@bth.se (K. Wnuk).

${ }^{1}$ SIPDO refers to organizations developing products or services with a substantial amount of software defining the product/service behavior, mostly embedded in physical products.
} 
Table 1

Definition of terms used in the study.

\begin{tabular}{|c|c|}
\hline Term(s) & Definition(s) \\
\hline Pecuniary & $\begin{array}{l}\text { Pecuniary resources refer to competitive assets, which are revealed against financial rewards, for example licensing proprietary software } \\
\text { tools }[8,12] \text {. }\end{array}$ \\
\hline Non-pecuniary & $\begin{array}{l}\text { Non-pecuniary resources refer to non-competitive assets, which are revealed without immediate financial rewards for a company [8,12], } \\
\text { for example, OSS tools (e.g., Jenkins and Gerrit) used in the development of proprietary products. }\end{array}$ \\
\hline Outside-In (or Inbound) innovation & $\begin{array}{l}\text { The inward flow of knowledge from outside the boundaries of an organization to inside }[12,23,58] \text {, for example, the extraction of } \\
\text { knowledge from OSS communities. }\end{array}$ \\
\hline Inside-out (or Outbound) innovation & $\begin{array}{l}\text { The outward flow of knowledge from inside the boundaries of an organization to outside }[12,23,58] \text {, for example, sharing the internal } \\
\text { knowledge of an organization to OSS communities. }\end{array}$ \\
\hline Coupled Innovation & $\begin{array}{l}\text { The outward and inward flow of knowledge from the boundaries of an organization }[12,23,58] \text {, for example, acquiring and sharing the } \\
\text { knowledge to OSS communities. }\end{array}$ \\
\hline
\end{tabular}

Table 2

Huizingh's classification of openness [27].

\begin{tabular}{lll}
\hline Innovation Process & Innovation Outcome \\
\cline { 2 - 3 } & Closed & Open \\
\hline $\begin{array}{lll}\text { Closed } \\
\text { Open }\end{array}$ & $\begin{array}{l}\text { Closed Innovation } \\
\text { Private Open Innovation }\end{array}$ & $\begin{array}{l}\text { Public Innovation } \\
\text { Open Source Innovation }\end{array}$ \\
\hline
\end{tabular}

OI has two important implications on the organizational structures [12]: (1) globalization enables increased division of labor, and (2) introduction of OSS enables professionals to seek for portfolio careers instead of working for a single employer. Therefore, SIPDOs need to find alternate ways of finding talented workers that might not be interested in exclusive or direct employments. Furthermore, intellectual property rights (IPR) utilization, technology standards, and venture capital allow software organizations to trade ideas.

Bosch [4] claims that speed, data and ecosystems are the main factors that impact SIPDOs in their software engineering practices. At the same time, the size of software-intensive products continues to grow. This growth incurs the need for faster and better adoption of applications, technologies, components, services, and ecosystem partners. In order to address this challenge, SIPDOs may utilize OSS communities to find more resources to increase the speed and reduce the development and maintenance costs. Linåker et al. [33] presented a Contribution Acceptance Process (CAP) model, which provides operational guidelines for SIPDOs regarding when and what features to contribute to OSS communities. CAP underlines four objectives for OI adaption: cost saving, time-to-market, control in the ecosystem, and strategic alliances and investments.

However, we have found no guidelines for SIPDOs in order to make strategic decisions regarding OSS tools, i.e. what role in Huizing's taxonomy to choose in the open innovation (i.e. open processes, open outcomes), for OSS tools which are not the core business (non-pecuniary) for the organization (e.g., OSS tools like Jenkins and Gerrit) but are vital to support the internal product development.

We present a theory of openness for software engineering tools in software organizations that complements and expands our previous research efforts $[39,42]$ and provides the necessary organizational aspects that support SIPDOs in their transformation towards OI. The scope of this study covers the use of non-pecuniary OSS tools in organizations' proprietary software development for outside-in and insideout innovation (i.e. coupled innovation). This study focuses on the strategic role of OSS tools in an organization, where we use software build tools as cases, due to their strategic role in the build chain [39] (Appendix A).

We synthesize the theory from two previous empirical studies $[39,42]$, complemented by a survey in the Git, Gerrit and Jenkins communities (Appendix A). The theory provides strategic guidelines and helps SIPDOs to adopt OI tools in relation to reduced development cost, shorter time-to-market and process, and product innovation.
The paper is structured as follows. Section 2 presents related work for this study, Section 3 provides an overview of the research methodology, and Section 4 shows the research synthesis process. Section 4 describes the narrative synthesis process, followed by Section 5 , which explains the Theory of Openness for Tools in software engineering. We conclude the paper in Section 6.

\section{Background studies and related work}

This work is conducted in the context of OI and OSS, which is explored in Section 2.1. We define theory for software engineering, and summarize thus related work on theory in SE in Section 2.2. Our recent systematic mapping study [42] and the case study on OI using OSS tools [39], as well as the validating survey presented in Appendix A are summarized in Section 2.3.

\subsection{Open innovation using OSS}

SIPDOs get involved in OSS communities to leverage their internal development resources, to steer the communities towards organizations' interest, to reduce time-to-market and development costs $[39,42]$. Increased openness towards OSS communities constitutes a challenge of keeping companies' competitive advantage while contributing software to OSS communities.

Our systematic mapping study [42] identified some of the OSS contribution strategies, such as engaging in OSS communities [14], open business models [7], and adopting selective revealing [24]. Furthermore, the knowledge acquired from OSS communities helps organizations to improve internal development processes, e.g., adopting continuous integration, leading to faster releases etc, which leads to product innovation [32].

However, it should be pointed out that OSS is not OI by definition. In order for an OSS project to be a representative example of OI, it is necessary that OSS is incorporated into the organization's business model and contributes to value creation in the organization's product development [39]. Thereby, OSS can be used to implement an OI strategy.

\subsection{Theory building in $S E$}

Theories offer common conceptual frameworks for more precise and structured organization of facts and knowledge. Theories also facilitate communication of ideas and knowledge through analytical generalization $[49,61]$. Many authors in the SE research community have raised concerns about lack of theories in SE $[1,2,20,26,48,51,55]$ and pointed on the limited nature of the work about SE theories.

The theory of distances by Bjarnason et al. [2] is an example creating a theory in SE [53]. Like their study, we also follow the guidelines provided by Sjøberg et al. [51] defining four theory constituents: the constructs (basic elements), propositions (interaction of constructs), explanation (reasons for propositions specification) and scope (application of the theory). 


\subsection{Background studies}

Three studies constitute the background for the theory creation: a systematic mapping study (S1), a case study (S2), and a survey study (S3).

S1 - A systematic mapping study was conducted to investigate OI in software engineering [42]. The findings suggest that a large majority of the studies have industry relevance. Therefore, we conclude that OI in software engineering is oriented towards industry practice. At the same time, the majority of studies were evaluation studies. This indicates a research gap in terms of conducting more solution and validation research.

Furthermore, the mapping study indicates that managers have too little time and resources to invest in significant contributions to OSS communities, even when an organization has a well defined OSS contribution strategy. Another important hurdle for organizations in embracing openness is the risk of losing intellectual property rights to competitors. In order to deal with it, business strategies are important to reveal a competitive asset and to avoid committing extra resources to commodity parts of the software. Thus, organizations can pursue a differentiation strategy with a controlled degree of openness.

The key message of the systematic mapping study is that the OI does not replace the existing R\&D capabilities of an organization. Rather, it complements or boosts the existing R\&D activities of an organizations to accelerate the innovation process.

S2 - The Gerrit/Jenkins case study was conducted to explore Sony Mobile's participation in the Jenkins and Gerrit communities and to highlight the innovation outcomes attached to coupled (inside-out and outside-in) OI processes [39]. The study describes the shift of Sony Mobile from using a closed innovation model to an open innovation model. This shift allowed Sony Mobile to utilize the Jenkins and Gerrit communities and improve their internal software development processes. We discovered that both small and large scale organizations are involved in the Jenkins and Gerrit communities along with Sony Mobile. However, Sony Mobile is the largest contributor in the development of aforementioned tools.

The key trigger that embraced openness at Sony Mobile was the paradigm shift from Windows to Linux development environments. However, this openness was limited to the tools that are not considered a direct source of revenue. Furthermore, they used dedicated internal resources (within the tools department), to gain influence and steer OSS communities towards its own business interests.

The study also underlines the lack of quantitative metrics to measure the effect of OI adaption on Sony Mobile's innovation capacity, but the qualitative data suggests more stability and flexibility in the internal development environment.

S3 - The survey in Jenkins, Gerrit and Git communities was designed to validate the findings from the case study, especially with respect to generalization to other SIPDOs. A questionnaire was distributed in the Jenkins, Gerrit and Git communities. Respondents include employees working in SIPDOs and OSS communities simultaneously and were classified as either users or contributors to OSS communities.

The results show that SIPDOs participate in OSS communities to bring in innovative ideas, save development costs, get the latest patches, gain control and influence communities for the organization's own process and product innovation. However, $62 \%$ of the respondents spent less than ten hours per week to work with OSS communities, which indicates that software organizations may not have fully understood the benefits of openness yet. The details from the survey are presented in Appendix A.

\section{Research design}

Most research in software engineering related to OI focuses on exploration of the OI notion [S1]. We identified a need to synthesize the existing knowledge in order to propose a solution to the problems faced by software organizations due to the adoption of OI using OSS tools. This study aims to find common themes among the three background studies [S1, S2 and S3], using a synthesis method adapted from Popay et al. [44] and Cruzes et al. [11].

\subsection{Research goals}

The scope of the research encompasses the use and impact of OSS tools on the internal software development of SIPDOs. First, we focus on the synthesis of factors associated with OI for OSS tools in SE literature. Second, we derived the theoretical constructs for OSS tools in SIPDOs from the synthesis. The first research goal is addressed in Sections 4.2.2-4.2.5, while the second research goal is addressed in Sections 4.2 .2 and 5.

\subsection{Narrative synthesis design}

We performed narrative synthesis [10,44], as summarized in Fig. 1. The synthesis integrates the systematic mapping study [S1], the Sony Mobile case study [S2], and the Git, Jenkins and Gerrit survey [S3], see Table 3. Furthermore, the findings of $\mathbf{S 1}$ were taken into account to design S2 and S3. The details of each step in Fig. 1 are explained in Section 4.

It is to be noted that $\mathbf{S} \mathbf{1}$ is a mapping study which contains 33 primary studies, addressing open innovation in SE. However, only 18 studies were selected from $\mathbf{S 1}$ for this work, which pertains to the scope of this study, and thereafter included in the synthesis process. The selected studies are listed in Table 3 next to S1. The selection criteria of the studies from $\mathbf{S 1}$ are as follows.

- Studies pertaining to the scope of OSS communities used by SIPDOs.

- Studies addressing the integration of external knowledge with internal knowledge (outside-in) in organization's software product development.

- Studies highlighting selective revealing (inside-out) of the internal knowledge to OSS communities by SIPDOs.

- Studies discussing the investment of organization's internal resources in OSS communities.

- Studies reporting the factors that encourage SIPDOs to choose openness in terms of processes and outcomes in relation to Huizing's classification (Table 2).

\section{Narrative synthesis}

The empirical evidence on OI for SE tools is synthesized according to the research design steps presented in Fig. 1.

\subsection{Developing a preliminary synthesis}

We developed preliminary synthesis based on the identified data. We performed an initial data assessment and concluded that the data is predominantly qualitative [44]. The pre-synthesis qualitative data comes from the systematic mapping study [S1] and the case study [S2]. Furthermore, a mix of quantitative and qualitative data is extracted from the survey study [S3]. The survey was distributed using Google forms and thus responses were stored in a Google sheet, which was downloaded to analyze the responses.

\subsubsection{Tabulating the data}

The first author extracted the data related to the first research goal, presented in Section 3.1. The data was stored from S1, S2 and S3 into a separate spreadsheet. The preliminary data extraction criteria include the organizations, the rationale behind adopting OI in software organizations, strategies, and the challenges faced by the organizations while working with OI. In Appendix C, Table C.12 shows a part of raw 


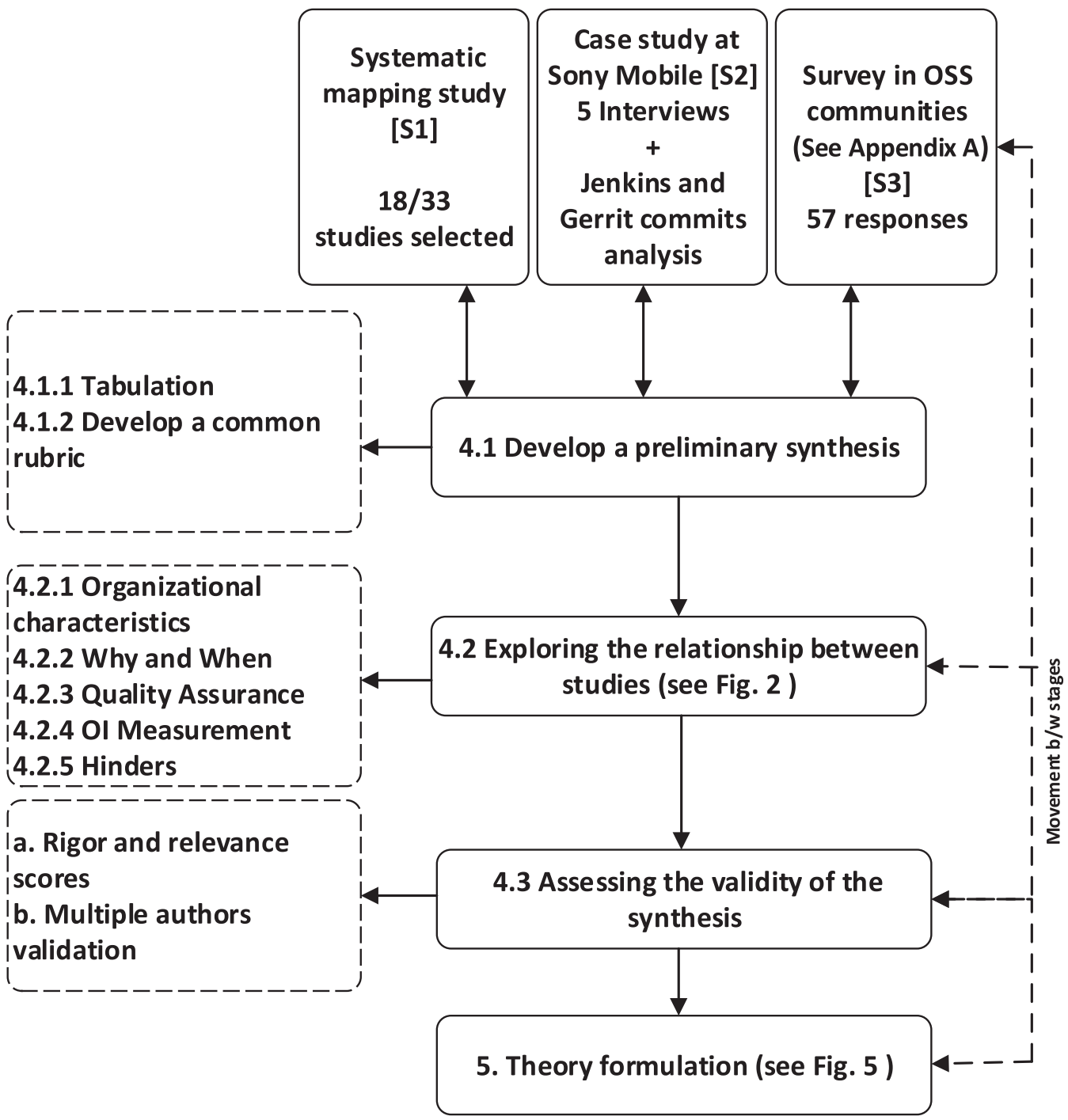

Fig. 1. Synthesis method and theory formulation. data collected from $\mathbf{S 1}, \mathbf{S 2}$ and $\mathbf{S 3}$.

Outcome: The outcome of this step is a table of raw data extracted from S1, S2 and S3.

\subsubsection{Developing a common rubric}

The first author defined a common rubric for all three studies. Next, the first author repeated the data extraction process from S1, S2 and S3 to ensure correctness and look for additional evidence. Initially, we did not find all the themes mentioned in Table 4. For example, the quality assurance and OI measurement themes were not obvious, but after collecting the data, these two new recurring patterns were identified.

Outcome: The result of this step leads to Table 4, which highlights the six joint rubrics from the preliminary data extraction process.

\subsection{Exploring the relationships between the studies}

We used the common rubrics outlined in Table 4 to identify the common characteristics between the systematic mapping study [S1], the case study [S2] and the survey in OSS communities [S3]. We wrote a short summary for each of the rubrics (tabular textual description) of each study [S1,S2,S3]. This allows accuracy and consistency checks with previous steps and helps to draw aspects from individual studies that may not have seemed relevant at the start of synthesis, but have become of interest during the subsequent stages of the synthesis.

Outcome: This step leads to the mind map presented in Fig. 2. Each of the categories mentioned in the mind map is discussed below.

\subsubsection{Organizational characteristics (Who)}

Both small and large companies use OSS tools as a means for OI. Fig. 3 shows the distribution of companies in $\mathbf{S 2}$ and $\mathbf{S 3}$ contributing or using OSS tools in their internal product development. The contextual details of the organizations such as name, product type, size and OSS tools can be found in Appendix B. From the contextual details of the studies in S1, it is not obvious whether they are contributors or non

Table 3

Studies used as a theoretical frame of reference.

\begin{tabular}{|c|c|c|}
\hline Study_ID & Study_name & References \\
\hline S1 & Open innovation in Software Engineering: a systematic mapping study [42] & {$[5,13,15-17,24,28,30,37,38,43,46,50,52,54,56,57,60]$} \\
\hline S2 & Open Innovation using Open Source Tools: a case study at Sony Mobile & [39] \\
\hline S3 & Survey on OI & [Appendix A] \\
\hline
\end{tabular}


Table 4

Definition of the joint rubrics for the three studies (S1-S3).

\begin{tabular}{|c|c|}
\hline Themes & Definition \\
\hline 1. Who & What characterizes the organizations involved in open innovation using OSS tools e.g., Jenkins, Gerrit, Git? \\
\hline 2. Why & Key factors considered by software organization before adopting openness \\
\hline 3. When & What are the strategies used by software organizations to be open? \\
\hline 4. Quality assurance & What are the tools used to automated test execution and the key challenges attached to software quality assurance in open innovation? \\
\hline 5. OI measurement & What metrics are used by software organization to measure the impact of Open innovation on development process? \\
\hline 6. Hinders & Challenges faced by organizations to adopt OI \\
\hline
\end{tabular}

contributors. Therefore, the companies included in this study are extracted from S2 and S3 only.

Fig. 3 shows that 16 software organizations are not only involved in using but also contributing back to OSS communities, such as Jenkins, Gerrit and Git. Out of the 16 contributing software organizations, 13 have more than 200 employees, see Fig. 2. This confirms that not only small software organizations are using OI but also larger organizations realize the importance of contributing to OSS communities to improve their internal development process. This observation is in line with the concept of process innovation [32] and the coupled open innovation process (inside-out and outside-in) [21].

\subsubsection{Why - When}

We explore the relation between the two themes entitled Why and When by creating a $2 \times 2$ matrix depicted in Fig. 4, which is referred as a visual representation of Why and When.

The horizontal axis of the model shows the two main driving forces related to the motivations for adapting OI; (1) Cost saving and (2) Inspiration. Firstly, the cost saving driving force refers to the aim of reducing the product development cost. Examples of cost saving entail incorporating an OSS solution instead of making it in-house, or spending more resources on differentiating features instead of on commodity features. The inspirational driving force refers to software engineers taking initiatives on their own to optimize the daily software engineering workflow by embracing openness. A typical example of inspiration is the employees working for SIPDOs that develop proprietary solutions, but also actively contribute to seek better solutions to OSS communities using the outside-in OI principle [21].

The vertical axis in Fig. 4, distinguishes between reactive and proactive OI adoption strategies. The reactive OI adoption strategy considers reacting to events rather than taking the leading role. In other words, the reactive strategy prevents software organizations from taking initiatives and they mostly adopt the wait-and-see strategy. On the contrary, the proactive OI adoption strategy enables organizations to anticipate what the future will be, and to react accordingly before a threat actually happens.

Empirical evidence of the aforementioned strategies is combined with the cost factor in Fig. 4. Each attribute in Fig. 4 can be traced back to its original study $\mathbf{S 1}, \mathbf{S 2}$ or $\mathbf{S 3}$, and each quadrant is described in detail below.

Reactive strategy - cost saving. The reactive strategy in relation to cost saving entails cost reduction of the development activities. The following are the attributes along with the definitions extracted from S1, S2 and S3.

A1 - A paradigm shift [S2]: Refers to the switch from Windows based software development environment to Linux [39].

A2 - Cheaper OSS solutions [S2, S3]: It is more cost effective for software organizations to adopt OSS code (even when integration efforts are substantial) instead of developing an in-house solution from scratch [39] (Appendix A).

A3 - Ease off the complex integration and building processes [S2, S3]: The introduction of OSS tools (Jenkins, Gerrit etc.) made the continuous integration process easier for software developers and testers [39], (Appendix A).

A4 - Cost of maintaining forks of the OSS code [S1, S2, S3]: To fork off the OSS code and its internal maintenance only makes sense if it adds significant value. In case of commodity software, it does not give any business advantage. Therefore, contributing commodity parts of the products alleviates software organizations from patching the code [39,46] (Appendix A).

A5 - When the product loses competitiveness [S2, S3]: Refers to making the project OSS in order to attract interest from the community

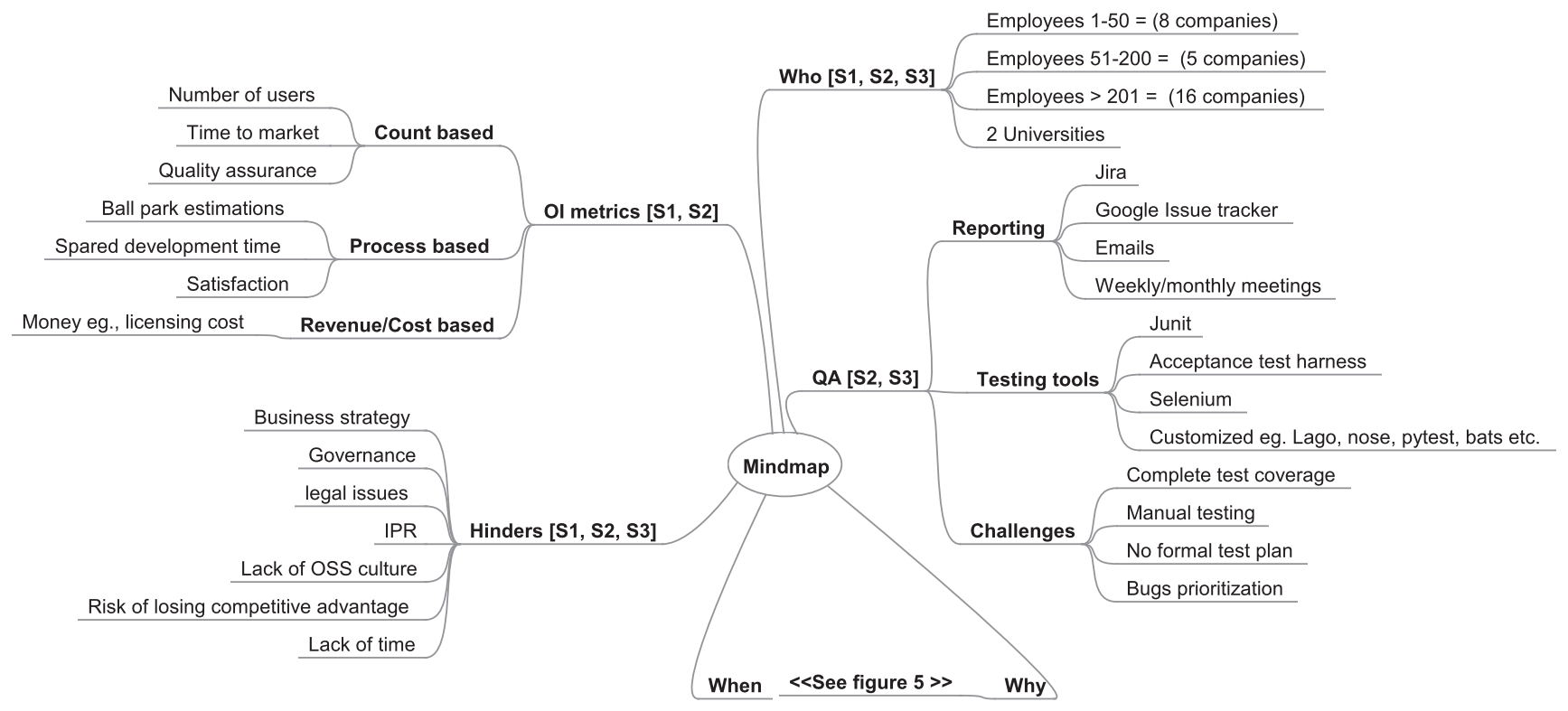

Fig. 2. Mind map of relationship between studies. 


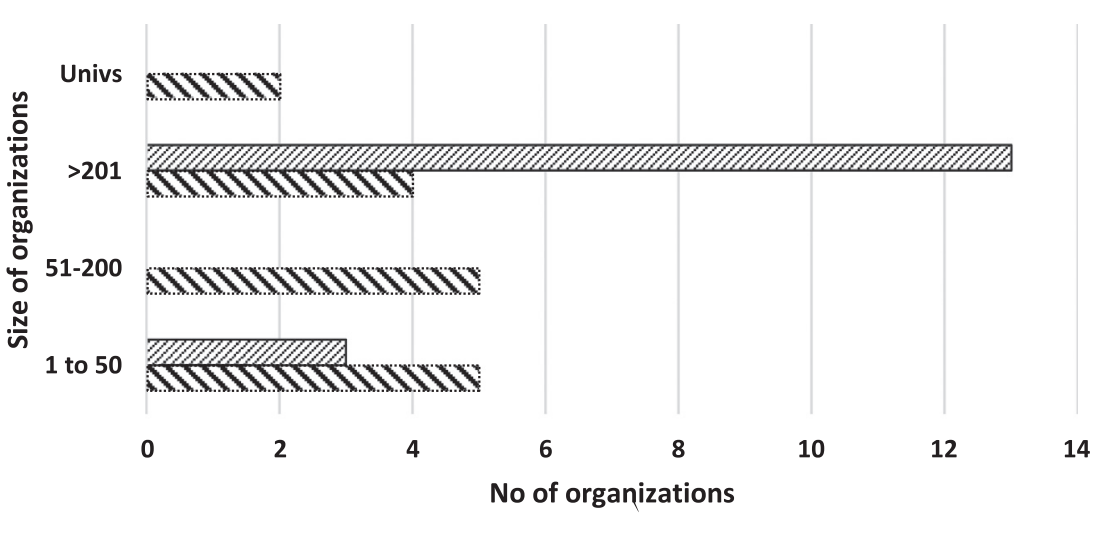

Contributors Non Contributors

and receive contributions as well. Making a product that loses competitiveness OSS also opens up for alternative revenue sources. Keeping the software closed only causes additional maintenance costs with no business benefits [39] (Appendix A).

A6 - Get the latest patches [S3]: This is also connected to costs of maintaining forks of OSS code. Organizations make the commodity code open to share the patching cost with the OSS community instead of spending unnecessary resources to maintain it internally [Appendix A].

A7 - Difficult to compete with the community's pace due to lack of resources [S1, S2, S3]: OSS communities are often comprised of skilled development work forces from around the world. It is difficult for software organizations to find such resources and hire them all $[13,39]$ (Appendix A).

A8 - Free new features and bug corrections [S1, S2, S3]: Refers to software organizations actively participating in OSS communities and in return receiving new features and free bug corrections to facilitate
Fig. 3. The number of contributors vs non contributors in S2 and S3, distributed over size categories.

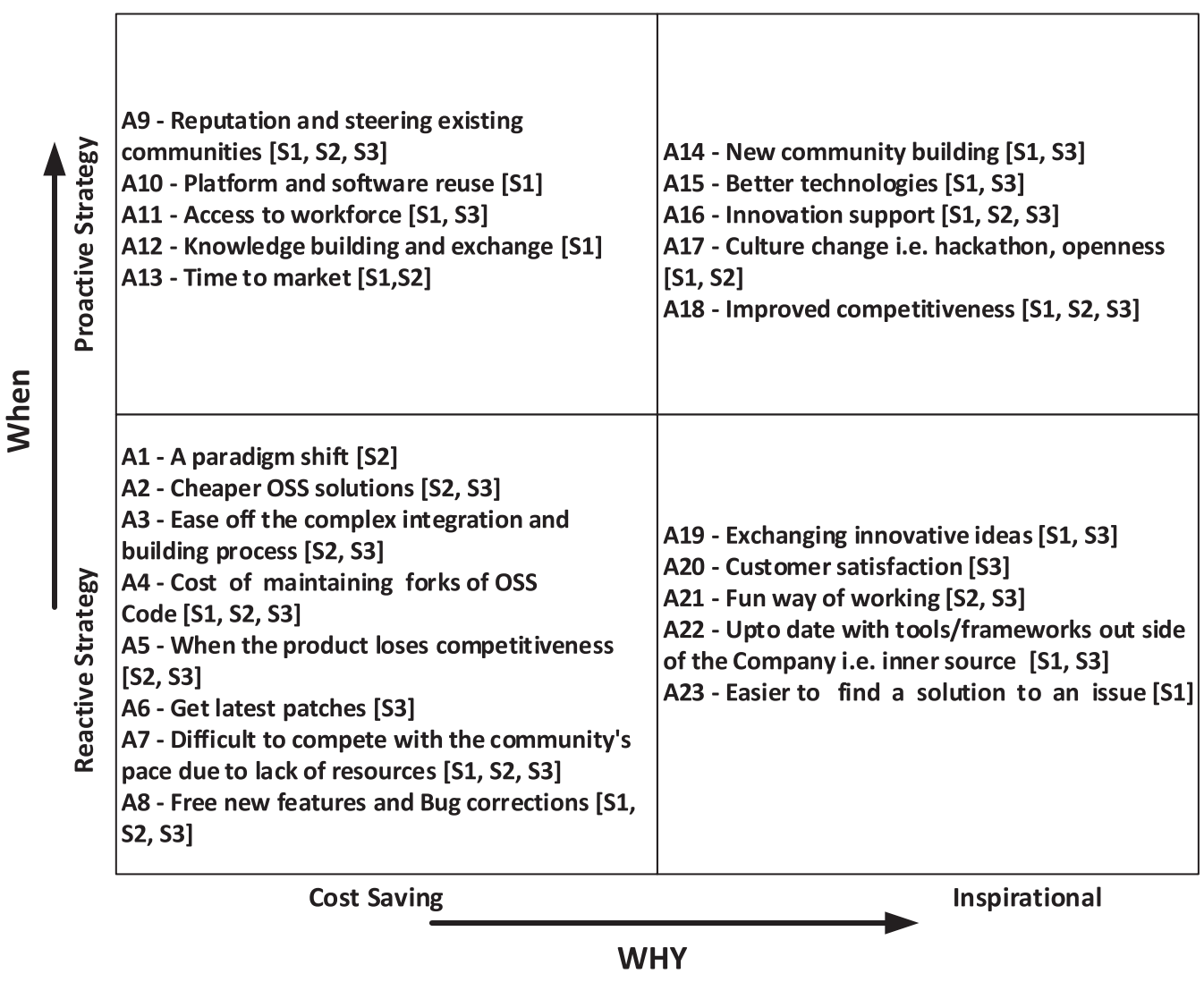

the development process [16,24,39,56,60] (Appendix A).

Summary. A factor that leads organizations to adopt the reactive cost saving strategy, is the substantial costs of proprietary tools vs. the much lower cost of using OSS tools. Therefore, many software organizations choose to switch from Windows to Linux development environments to ease off the complex source code integration and building processes [39]. Factors that motivate organizations to adopt reactive cost saving strategies include patching cost, products losing their competitive advantages, to get new features, licenses that demand organization to contribute back, and difficulty to keep up with evergrowing OSS communities (Appendix A). Forking an OSS solution leads to internal maintenance of commodity software. As the core of the reactive strategy is to save maintenance costs, organizations choose to open up commodity solutions and share the maintenance cost with all stakeholders in the community.

Proactive strategy - cost saving. The following attributes are extracted in relation to the proactive cost saving strategy.
Fig. 4. Visual representation of Why and When. 
A9 - Reputation and steering existing communities [S1, S2, S3]: Refers to becoming an active contributor in OSS communities and influence or steer these communities towards organizational interests $[15,39,54]$ (Appendix A).

A10 - Platform and software reuse [S1]: Refers to reusable software components used together with proprietary software in the products [37].

A11 - Access to workforce [S1, S3]: Refers to the utilization of smart development workforce, which does not work directly for an organization, but possible to utilize through OSS communities $[15,24]$ (Appendix A).

A12 - Knowledge building and exchange [S1]: Refers to in-flows and out-flows of knowledge in software organizations $[5,13,28,30,37,52,54,57]$.

A13 - Time to market [S1, S2, S3]: Adopting the commodity code from OSS communities is not only cheaper but also reduces the time it would require to develop that code in-house [37,39,54] (Appendix A).

Summary. The proactive cost saving strategy allows SIPDOs to engage in OSS communities and become their trustworthy member to steer communities toward their own business models and use the community developers for organizational focused development. This, in turn, makes it possible for organizations to access all the software developers, that exist beyond the organizational borders, without hiring them. Organizations are required to invest in existing communities to reduce the time-to-market and development costs by utilizing developers from OSS communities.

Proactive strategy - inspirational. The following attributes are extracted in relation to the proactive inspirational strategy.

A14 - New community building [S1, S3]: This is one of the ways to further enhance the organization's internal innovative capacity. It is desired by organizations when existing communities are not fulfiling the expectations of the organizational needs $[13,15,28,38]$ (Appendix A).

A15 - Better technologies [S1, S3]: Refers to building new features with the help of, or suggestions from, hundreds of developers in the community in relation to a handfull of developers inside the organization [37,38,52,54] (Appendix A).

A16 - Innovation support [S1, S2, S3]: Refers to complementing the organization's internal R\&D process by indulging organizational resources into OSS communities and using this knowledge to improve the organizations' innovative capacity [28,37,39,43,54] (Appendix A).

A17 - Culture change [S1, S2]: Deals with promoting the embracing of an openness culture in product and process development, without the fear of losing competitive advantage and being able to solve problems using hackathons $[39,50]$.

A18 - Improved competitiveness [S1, S2, S3]: This is primarily in relation to decreased time-to-market. Using OSS code helps organizations to get their products out in the market faster and thus increase competitiveness [37,39,54] (Appendix A).

Summary. The proactive inspirational strategy driven by the managers provide inspiration to create new communication channels between developers belonging to different organizations. The objective is to build new OSS communities if the existing communities are not supporting the organization's internal innovation processes. Software development teams empowered by proactive strategies, search for innovative solutions and embrace an openness culture (e.g., hackathons) for the shared knowledge building. Consequently, the exploration of the proactive strategy frees up time for development teams to focus on differentiating tasks, which improves competitiveness and supports internal innovation.

Reactive strategy - inspirational. The following are the definitions of factors relevant to inspire developers in an organizations by working with OSS communities.

A19 - Exchanging innovative ideas [S1, S3]: Refers to utilizing OSS communities as a forum for exchanging ideas and helping each other $[13,17,37]$ (Appendix A).

A20 - Improved customer satisfaction [S3]: Continuous development and software updates lead to improved customer satisfaction (Appendix A).

A21 - Fun way of working [S2, S3]: Software developers involved in OSS communities find it a fun way of working. Furthermore, organizations also use communities to keep their workforce motivated by finding news way of working [39] (Appendix A).

A22 - Up-to-date with tools/frameworks [S1, S3]: Allows software developers to stay up-to-date with the new tools/frameworks outside the organizational border, using OSS communities. In addition, it allows developers to acquire knowledge from OSS communities and integrate that across different units of an organization [37] (Appendix A).

A23 - Easier to find a solution to an issue [S1]: Gives software developers in organizations the possibility to look for solutions to their problems beyond organizational borders [37].

Summary. The reactive inspirational strategy leads organizations to use OSS communities for the exchange of ideas and helps developers to find better solutions. To keep the motivation and to be up-to-date with the tools, organizations encourage their developers to engage in OSS communities. Furthermore, developers find it easier to find a solution to their problems by being open.

\subsubsection{Quality assurance}

Quality assurance in relation to OI is an under-researched area, while there are several challenges in testing the OSS tools. For organizations who have to test OSS tools together with OSS communities (e.g., Jenkins, Gerrit), they identify the need of automated testing. However, it is still not possible to have a complete test coverage due to many configuration settings and the open nature of these tools, but automation helps developers to identify the defects quickly [41].

Out of the survey respondents (Appendix A), 34.5\% highlighted that manual testing consumes too much time, and there is a need for an automated testing framework. The Jenkins community introduced an acceptance test harness [41], which is an automated test suite to test Jenkins core and its plug-ins. However, the Gerrit community is not as mature as the Jenkins community, and the community is trying to replicate the automated testing harness from Jenkins. Further details of quality assurance from the survey can be found in A.4.

\subsubsection{OI measurement}

We identified evidence regarding the metrics used by software organizations to measure the impact of OI as reported in Table 5.

Table 5

Metrics to measure Open Innovation.

\begin{tabular}{|c|c|c|}
\hline OI Measurement & Metrics & Definition \\
\hline \multirow[t]{3}{*}{ Count measures } & Number of users [S3] & Number of users using OSS tools \\
\hline & Time to market $[\mathrm{S} 2, \mathrm{~S} 3]$ & Measure the time difference with and without OSS tools \\
\hline & Quality assurance [S3] & Frequency of bugs using with or without using OSS tools \\
\hline \multirow[t]{3}{*}{ Process measures } & Ball park estimations [S2] & How much development up-time lost if the organization is not able to quickly fix the show stopper bugs \\
\hline & Spared development time [S2,S3] & Time required for own developed solution vs OSS \\
\hline & Satisfaction [S3] & Five point Likert scale from Not at all satisfied to somewhat satisfied \\
\hline Revenue/Cost based measures & Money $[\mathrm{S} 2, \mathrm{~S} 3]$ & Licensing cost of OSS vs non-OSS tools \\
\hline
\end{tabular}


We categorized these measures based on the criteria provided by Edison et al. [18] and divided them into the three categories: (1) count measures (number of users, time taken to introduce new products in the market, etc.), (2) process measures (assess the innovation capability of an organization), (3) revenue and cost measures (money, licensing cost). It must be mentioned that these metrics came up as suggestions from interviewees [S2] and survey respondents [S3].

\subsubsection{Hinders}

Embracing openness is also associated with barriers. The lack of time, resources and understanding of OSS communities hinders organizations to commit the resources dedicated for OSS communities [S1, S3]. Although, software organizations recognize the benefits of participating in or creating a strong community, there are a few limitations associated with it. Those limitations entails management constraints due to the lack of funding, understanding, contributor agreements lawyers/significant internal paperwork, unfamiliarity, distrust with regards to OI contribution strategies of working [39] (Appendix A).

Executives and R\&D legal experts need to evaluate OSS contributions for licensing, protecting organization's IP rights and patent infringements [S2]. The value of being in control of an OSS community is not well understood [S3]. Moreover, a slow approval process [S2] for contributions also leads to lack of motivation among employees to contribute to OSS communities. This is also connected to working with the development methodology (Scrum) since there is no room in the sprints to prioritize OSS contributions $[9,39,60]$.

\subsection{Assessing the validity of the synthesis}

We used the rigor and relevance criteria followed by multiple authors validation in which all authors were involved in validating the synthesis process to test the validity of the synthesis.

We applied the criteria, previously used by Munir et al.[40] to the case study [S2] and survey [S3] underpinning this work, see Table 6. The rigor and relevance criteria used for [S2] and [S3] are available in D.1 and D.2. Scores between 0 and 1.5 are considered as low rigor, while high rigor entail scores of 2 or above. On the other hand, studies with the score from ( 0 to 2 ) have low relevance, while scores from 2.5 or above are seen as high relevance. The systematic mapping study [S1] was not scored based on the criteria because the criteria are not meant for literature reviews. However, the study $\mathbf{S} 1$ itself used the rigor and relevance criteria to rate all the primary study used in the synthesis process.

Below, the four types of validity threats $[45,47]$ related to the synthesis are addressed with their mitigation strategies.

\subsubsection{Internal validity}

Internal validity refers to causal relationships and the introduction of potential confounding factors [47].

Peer examination. The objective behind conducting the synthesis study was to generate theoretical guidelines based on the three studies that explored OI in software engineering. Since the data synthesis process entails qualitative data, this introduces the risk of subjectivity. In order to minimize this risk, the second and third authors were involved in validating the synthesis.

The theoretical foundation for the theory of openness for software engineering tools in software organization included studies S1, S2 and S3. However, S1 comprised of studies where the scope of the few

Table 6

Rigor and relevance scores for the studies.

\begin{tabular}{llllllllll}
\hline Ref. & C & D & V & Rigor Sum & U & S & RM & C & Rel. SUM \\
\hline S2 [39] & 1 & 1 & 1 & 3 & 1 & 1 & 1 & 1 & 4 \\
S3 (Appendix A) & 1 & 1 & 1 & 3 & 1 & 0.5 & 1 & 1 & 3.5 \\
\hline
\end{tabular}

studies was not limited to OSS tools only, while the theory of Openness is limited to OSS non-competitive tools. The underlying phenomena may be different and thus present a validity threat to the theory.

\subsubsection{External validity}

External validity deals with the extent to which it is possible to generalize the study findings to other contexts [47]. Merriam [35] viewed external validity from the perspective of assumptions underlying qualitative research and proposed several reformulations of generalizations such as working hypothesis, concrete universals and readers or user generalizations.

In this study concrete universals [22] seems more applicable where a particular context is applied to similar contexts subsequently encountered. The context in this study refers to SIPDOs using OSS tools in their internal software development. To be specific, $\mathbf{S 2}$ presents a case study at Sony Mobile using OSS tools (e.g., Jenkins, Gerrit, Git) in their proprietary software development and S3 contains 26 organizations either using or contributing to OSS communities. The contextual details of each organization are presented in Appendix B. The broad representation of organizations that support the findings of this study, indicate generalizability to organizations using OSS tools for their internal software product development.

\subsubsection{Construct validity}

This deals with choosing the suitable measures for the concepts under study. This study used two primary and 18 secondary studies from $\mathbf{S 1}$ for narrative synthesis. Although, it is possible to use secondary studies for narrative synthesis, the difficulty in achieving the abstraction of results at the same level presents a validity threat. In order to minimize this risk, studies $\mathbf{S} 2$ and $\mathbf{S 3}$ were conducted by taking inputs from the findings of $\mathbf{S 1}$, which enables researchers to find common relationships among studies for the comparison (see Table 4).

The survey study is susceptible to the threat of subjects trying to guess the intent of the study and altering their behavior. Further, we use the survey in OSS communities to understand whether or not openness helps organizations to accelerate the organization's internal development process. This introduces the risk of respondents guessing the hypothesis correctly and start responding from community's view point to be more open. Consequently, the respondents may completely ignore the organizational interest to affect the results, which can be used to convince software organizations to be open even when it is not desirable for an organization to be open. To mitigate this risk, all respondents were clearly instructed to answer the survey questions according to their associated organizational unit instead of OSS communities.

\subsubsection{Reliability}

The reliability deals with to what extent the data and the analysis are dependent on the specific researcher, and the ability to replicate the study.

Member checking. All three authors analyzed the extracted data from the studies included in the related work. Furthermore, the guidelines provided by Popay et al. [44] were used to make the synthesis process objective, reliable, transparent and repeatable.

Audit trail. The first author kept track of all the data sheets created from the studies and monitored data consistency and correctness during the synthesis iterations.

\section{Theory formulation}

Based on the synthesized empirical evidence, summarized above, we here present the the theory of openness for software engineering tools in software organizations, according to the theory-building framework proposed by Sjøberg et al. [51]. According to the framework, a theory consists of: (1) constructs, (2) propositions, and (3) explanation, outlined in the subsections that follow. 


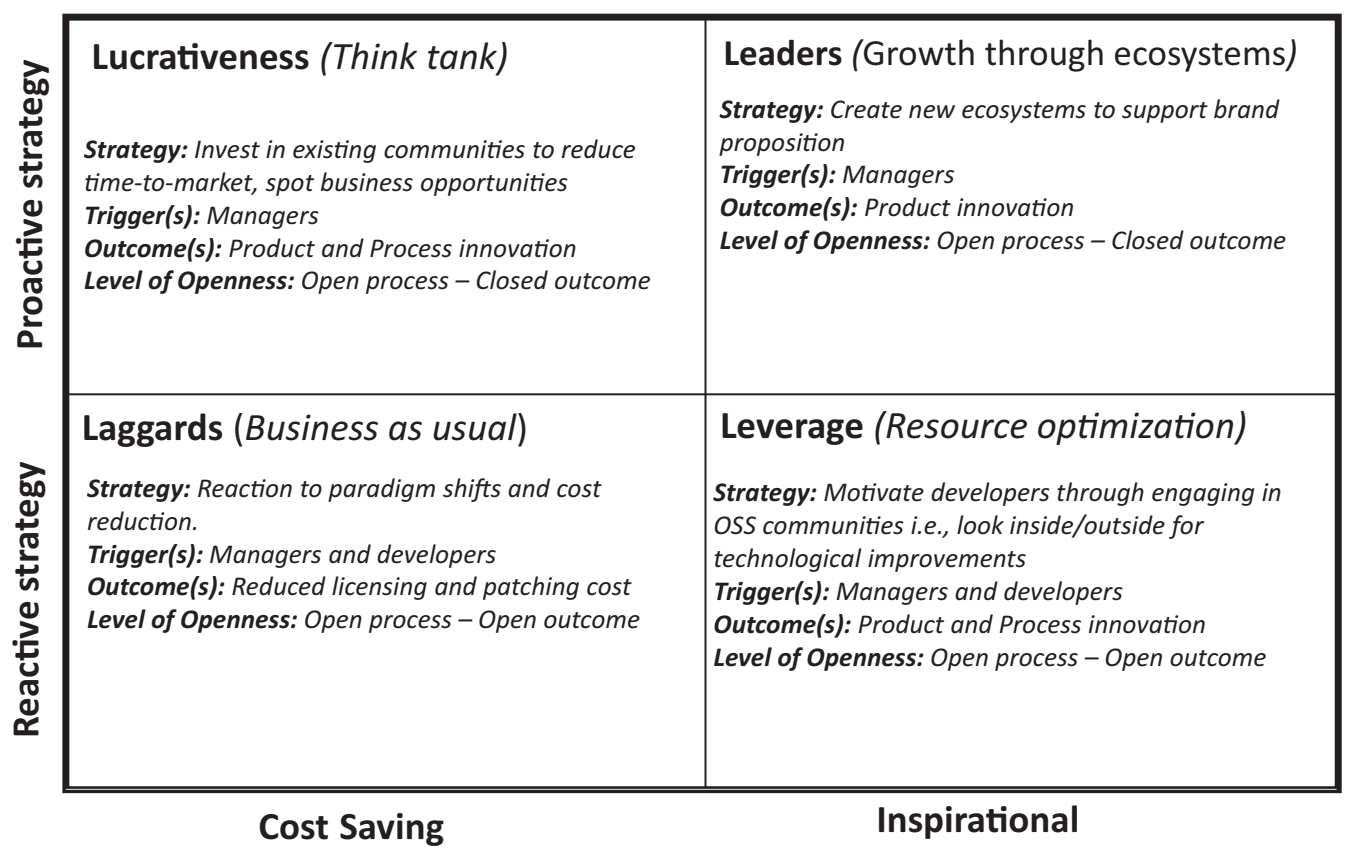

Fig. 5. Model of Openness for Tools.

\subsection{Defining constructs for the Theory of Openness for Tools}

We derived four constructs from the visual representation of When and Why in Fig. 4: Strategy, Trigger(s), Outcome(s), and Level of openness. These are abstracted during the data synthesis, as described in Fig. 1. The synthesis also resulted in a further abstracted openness model, presented in Fig. 5. Furthermore, the mapping of constructs from the attributes in openness model is shown in Table 7. The definitions of constructs are below.

Strategy refers to managerial decisions on when and why a software organization should only use or use and contribute to OSS tools communities (e.g., Jenkins, Gerrit etc.). An example strategy is to engage software developers in OSS tools communities (A14) for knowledge building and exchange of innovative ideas to support innovation (A15, A16) in organizations' proprietary products. Furthermore, when the product loses it competitiveness (A5), it could become a candidate to become open source to create a community around it. Consequently, it helps SIPDOs to create a good reputation in the community and steer them towards their own needs (A9, A20).

Trigger(s) highlight(s) the actors involved in either decisionmaking of openness or its implementation(e.g., managers and software developers). The initial trigger might come from managers as a result of paradigm shift (e.g., switch from Windows to Linux) or from software developers due to complex continuous integration process (A1, A3). For example, S2 showed a case where Sony Mobile switched from a proprietary tool ElectricCommander to an OSS tool Jenkins because it was easier to find solutions (A23) in OSS communities and adopt the tools according to the internal development work-flow (A19).

Outcome(s) deal(s) with the affect (implications) of adopting openness for tools in SIPDOs. Reduction in the development cost can be achieved by choosing open tools instead of licensed tools in SIPDOs for the internal software development (A2). It not only allows developers to stay up to date with their tool chain (A22), but also provides an opportunity for an organization's employees to interact with the developers in the tools communities (A11) and receive free new features and bugs corrections (A8). Open tools make the internal development environment more flexible since the developers themselves can enhance the tool to better suit their needs. Consequently, it can have an impact on the reduced development time which leads to shorter time-to-market (A13).

Level of openness entails the extent to which an organization should be open, which may be a property of both the development process and the outcome, according to Huizingh et al. [27]. For example, an openness of the development process for a SIPDO may include arranging a hackathon with tools community developer to allow internal developers to work together to implement new functionality (A7, A17). On the outcome level, an organization may choose to release the code to OSS communities instead of maintaining an internal fork for a commodity code (A4). Forking will only lead to more patching and code maintenance every time there is a new release from the community. Therefore, choosing the right level of openness may allow the organization to share the maintenance cost with the community to free up the internal developers time by receiving the latest patches from the community (A6).

\subsection{Propositions for the Theory of Openness for Tools}

The deduction of propositions can be traced back to constructs and attributes, see Fig. 4) and Table 7.

Proposition 1 (P1) Openness of tools provides opportunities to reduce development costs.

P1 relates to two constructs: (1) Level of openness and (2) Outcome (s). Openness of tools can lead to reduced development costs for multiple reasons. First, instead of "re-inventing the wheel" software organizations can choose the OSS tools already developed (A11, A2). Second, the costs of maintaining software can be shared with OSS communities (A4, A6) as showed by $\mathrm{S} 2$.

Proposition 2 (P2) Openness of tools provides opportunities to shorten the development time.

P2 relates to two constructs: (1) Level of openness and (2) Outcome (s). Openness of tools may lead to shorter development time (A13) due to the following reasons. First, bugs related to OSS tools (e.g., Jenkins and Gerrit) could be fixed by the organization itself since they have access to the source code of the tools or they may receive fixes (A8) from community developers (S2). Second, software reuse (A10) and free features and bug fixes from communities enable software organizations to shorten the development time. S3 (Appendix A) shows that contributors (57\%) and non-contributors (59\%) to OSS communities think that openness reduces development time. 
Table 7

Attributes (see Fig. 4) mapping between constructs and proposition.

\begin{tabular}{|c|c|c|}
\hline ID (s) & Construct (s) & Proposition (s) \\
\hline $\mathrm{A} 9[\mathrm{~S} 1, \mathrm{~S} 2, \mathrm{~S} 3]$ & \multirow{7}{*}{ Strategy } & \multirow{3}{*}{ P4 - Degree of investment } \\
\hline $\mathrm{A} 16[\mathrm{~S} 1, \mathrm{~S} 2, \mathrm{~S} 3]$ & & \\
\hline A20 [S3] & & \\
\hline A5 [S2, S3] & & \multirow{4}{*}{ P5 - Requires management approval } \\
\hline $\mathrm{A} 12[\mathrm{~S} 1]$ & & \\
\hline $\mathrm{A} 14[\mathrm{~S} 2, \mathrm{~S} 3]$ & & \\
\hline $\mathrm{A} 15[\mathrm{~S} 1, \mathrm{~S} 3]$ & & \\
\hline $\mathrm{A} 1[\mathrm{~S} 2]$ & \multirow{4}{*}{ Triggers } & \multirow{2}{*}{ P3 - Process and product Innovation } \\
\hline $\mathrm{A} 3[\mathrm{~S} 2, \mathrm{~S} 3]$ & & \\
\hline $\mathrm{A} 23[\mathrm{~S} 1]$ & & P4 - Degree of investment \\
\hline $\mathrm{A} 19[\mathrm{~S} 1, \mathrm{~S} 3]$ & & P5 - Requires management approval \\
\hline $\mathrm{A} 2[\mathrm{~S} 2, \mathrm{~S} 3]$ & \multirow{6}{*}{ Outcomes } & \multirow{2}{*}{ P1 - Reduce development cost } \\
\hline A11 $[\mathrm{S} 1, \mathrm{~S} 3]$ & & \\
\hline $\mathrm{A} 8[\mathrm{~S} 1, \mathrm{~S} 2, \mathrm{~S} 3]$ & & \multirow{2}{*}{ P2 - Shorten development time } \\
\hline $\mathrm{A} 13[\mathrm{~S} 1, \mathrm{~S} 2]$ & & \\
\hline $\mathrm{A} 18[\mathrm{~S} 1, \mathrm{~S} 2, \mathrm{~S} 3]$ & & \multirow{2}{*}{ P3 - Process and product innovation } \\
\hline $\mathrm{A} 22[\mathrm{~S} 1, \mathrm{~S} 3]$ & & \\
\hline $\mathrm{A} 4[\mathrm{~S} 1, \mathrm{~S} 2, \mathrm{~S} 3]$ & \multirow{6}{*}{ Level of Openness } & \multirow{2}{*}{ P1 - Reduce development cost } \\
\hline $\mathrm{A} 6$ [S3] & & \\
\hline $\mathrm{A} 10[\mathrm{~S} 1]$ & & P2 - Shorten development time \\
\hline $\mathrm{A} 7[\mathrm{~S} 1, \mathrm{~S} 2, \mathrm{~S} 3]$ & & \multirow{3}{*}{ P3 - Process and product innovation } \\
\hline $\mathrm{A} 17[\mathrm{~S} 1, \mathrm{~S} 2]$ & & \\
\hline $\mathrm{A} 21[\mathrm{~S} 2, \mathrm{~S} 3]$ & & \\
\hline
\end{tabular}

Proposition 3 (P3) Openness of tools complements internal processes and product innovation.

P3 links to three constructs: (1) Level of openness, (2) Outcome(s), and (3) Trigger(s). S2 shows that the use of Gerrit and Jenkins communities in Sony Mobile's internal software development, leads to better internal development environment (e.g., continuous integration). The initial trigger of open tools came from the complex integration and building process (A3) and the shift from Windows to Linux (A1) As an outcome of this openness towards tools, it introduced a new fun way of working with tool communities for internal developers (A17, A21). Moreover, it enabled other units of Sony (e.g., Sony Entertainment) to replicate (inner source initiatives) the same development environment (A22), without having to pay for it. The better internal development process due to the openness towards Jenkins and Gerrit communities can be seen as an example of process innovation, which in-turns affects the improved competitiveness in products (A18).

Proposition 4 (P4) The degree of investment in OSS communities has an affect on the outcome.

P4 relates to two constructs (1) Trigger(s) and (2) Strategy. SIPDOs may need to invest in OSS tools communities to build the reputation (A9), which helps organizations to gain influence and control over the communities (S2, S3). Consequently, an organization may have a better support external support for their internal product innovation (A16, A20).

Proposition 5 (P5) Introducing a proactive strategy, in relation to openness of tools, requires conscious management involvement.

P5 refers to two constructs (1) Trigger(s) (2) Strategies. The idea of acquiring the external knowledge (A19) to support internal innovation
(A12, A15) may require organizations to move from a closed innovation model to an open innovation model. One such example is the creation of new open tools communities (A14), if the existing communities are not in-line with the organization's business model. This proposition is hinting that management may have to make proactive strategies to harness the power of internal employees, as well as the outside crowd in OSS communities, while still safeguarding the competitive edge (S3).

\subsection{Explanation of the Theory of Openness for Tools}

The synthesized model, underpinning the theory of openness for software engineering tools in software organizations, is presented in Fig. 5. The constructs of the theory, and instances thereof, are presented in boldface in the description below.

The theory explains four categories of organizations, represented by the quadrants in Fig. 5. Each category has the different levels of openness, based on their strategies (proactive orreactive) in relation to goals (cost saving or inspirational) and associated with propositions (see Table 7). The theory presents four classifications of openness with their respective focus: (a) Laggards - Routine business, (b) Leverage - Resource optimization, (c) Lucrativeness - Acting as a think-tank, and (d) Leaders - Growth through ecosystems.

\subsubsection{Laggards (reactive strategy - cost saving)}

The underlying assumptions for the laggards is that they respond to paradigm shifts and all strategies are reactive in order to reduce the development cost, wanting to run business as usual. Organizations that position themselves in this quadrant understand that their software tools are not competitive and that alternative options are available, often as OSS. Studies indicate $[3,33,34]$ that in the absence of intellectual property rights, there may be greater chances of commutative 
advancements and reduction of the patching cost, by avoiding forking of OSS.

For example, the introduction of Git made IBM's ClearCase an expensive proposition for SIPDOs due to licensing costs. Forking an OSS tool for internal use may lead to patching costs (e.g., internal maintenance) as a result of new releases from the community. Therefore, managers and developers in organizations categorized as laggards should keep their development processes and outcomes open in order to receive all the latest updates from the community without patching it.

\subsubsection{Leverage (reactive strategy - inspiration)}

Organizations that are categorized in the leverage category, use external sources of innovation by inspiring their internal developers to participate in various OSS communities, prior to internal R\&D work. The objective is to create synergy and synchronization between the organization's own processes and externally available ideas that could be incorporated in products, thereby optimizing the resources of the organization. This is a deliberate ploy from managers to absorb the external ideas and to make them fit for internal process. Furthermore, it not only adds to product and process innovation, but also inspires developers to participate in the discussion forums and exchange ideas to develop competence. The participation of organizations in communities like Opensource.com [59], Gerrit [39], and Acceptance test harness [41] are examples of open principles of catalyzing a community and engaging people through a common platform.

\subsubsection{Lucrativeness (proactive strategy - cost saving)}

Lucrativeness deals with investing in existing OSS communities to be able to influence and steer these communities in the same direction as the organizational interests, functioning as a think-tank for the organization. The objective is to support internal innovation and reduce costs by investing in OSS communities. The use of platforms helps organizations to reduce time-to-market. The key goal for the organization is to build the capability for its employees to make independent decisions, act quickly, take initiatives, and creatively solve problems. However, this goal requires employees' engagement, which need to be recognized by the managers. In order to make this work, managers need to ensure that processes are open for the exchange of ideas, but innovation outcomes are closed to achieve the competitive edge.

For example, CloudBees used Jenkins and added an extra layer of enterprise-grade security, scalability, manageability and expert-level support to improve the continuous integration in enterprise applications and started selling their product portfolio based on differentiation. Therefore, CloudBees utilized on Proactive - Cost saving strategy to not only reduce cost but also created a business opportunity to create revenue.

\subsubsection{Leaders (proactive strategy - inspiration)}

Leaders are organizations who look for emerging markets and breakout technologies by identifying the set of target areas, in order to create growth through ecosystems. These target areas are identified using lucrativeness. This is a top down exercise tied to strategic product planning lead by top management. The focus is on creating new communities and ecosystems that have the ability to disrupt business models.

For example, Sony created an ecosystem by making an Authoring Tools Framework (ATF) open source, which is used to make game development tools on Windows. It relieved PlayStation developers from contract barriers and made it quicker, easier and cheaper for developers to create development tools and game engines. By creating an ecosystem, Sony not only reduced the game development cost for its users but also strengthened the use of its PlayStation. The key is to safe-guard the competitive edge by keeping the processes open.

\subsection{Definition of scope for the Theory of Openness for Tools}

The scope defines the boundaries under which the theory of openness for software engineering tools in software organizations holds. We follow the advice of El Eman et al. [19], to "be sure to specify as much of the industrial context as possible. In particular, clearly define the entities, attributes and measures that are capturing the contextual information".

This information about the software organizations underpinning the theory, is addressed in Section 4.2.1 and reported in detail in Appendix B. It includes all software organizations, either only using or contributing as well to OSS communities, from which the empirical evidence is collected. Appendix B highlights the size, roles and OSS tools used by the software organizations that are adopting openness. Below we summarize the scope in terms of technology, actors and software systems.

\subsubsection{Technology}

Scope of validity: The use of OSS communities in the internal development of a software organization is compulsory. The organizations size may range from 1-50, 51-200 or > 201 as mentioned in Fig. 3.

Scope of interest: The knowledge extraction from OSS communities to facilitate organization's internal process, product innovation and reduced development time.

\subsubsection{Actors}

Scope of validity: Actors include software developers and managers. Software developers are employees associated with software organizations and also active members of OSS communities.

Scope of interest: To engage internal developers from SIPDOs in OSS tools communities for process and product innovation.

\subsubsection{Software systems}

Scope of validity: Although the case study [S2] included in the synthesis process was performed at Sony Mobile with the focus on using and contributing to specific OSS tools communities, namely Jenkins and Gerrit, the survey includes software organizations with the wide range of OSS tools mentioned in Tables B.10 and B.11, the column Product type.

Scope of interest: Projects that involve the use of OSS tools.

\subsection{Theory evaluation}

In this section, we evaluated the Theory of Openness for Tools using the criteria proposed by Sjøberg et al. [51]. The criteria are comprised of testability, empirical support, explanatory power, parsimony, generality and utility. For each criterion, we rated Theory of Openness on the scale of low, moderate or high.

\subsubsection{Testability}

The theory of openness for software engineering tools in software organizations presents understandable, consistent and unambitious constructs and propositions from the viewpoint of software developers and managers. Hypotheses are derived from the propositions since the scope conditions are clearly defined in the previous section. However, the adoption of OI using OSS needs to be understood by the readers in order to understand the theory.

There are a few studies conducted on the definition of openness in OI $[12,23,31]$. However, in this study, we choose the openness classification by Huizingh [27] since it was related to the opening of processes and outcomes, and the theory of openness has the level of openness as a construct (see Section 5.1).

We intend to validate the theory by conducting a workshop in multiple companies using OSS tools for their proprietary software product development. The workshop will be performed in two steps. In the first, the participants will be asked to select a tool from their own 
Table 8

Empirical evidence to support propositions. P1, P2, P3, P4 and P5 represent propositions mentioned in Section 5.2.

\begin{tabular}{|c|c|c|}
\hline Proposition & Evidence & Summary \\
\hline P1 - Reduce development cost & {$[38,39,54]$} & E.g., reduced licensing cost, patching cost \\
\hline P2 - Shorten development time & {$[37,39]$} & E.g., reuse of OSS, outsourcing of software testing and bug fixing and maintenance \\
\hline P3 - Process and product innovation & {$[25,37-39,43,50,52,54]$} & $\begin{array}{l}\text { E.g., faster testing and debugging, better work-flow management for developers, free-up time, incremental } \\
\text { innovation, better continuous integration }\end{array}$ \\
\hline P4 - Degree of investment & [43] & Positively associated with radical and incremental innovation \\
\hline P5 - Requires management approval & {$[25]$} & E.g., creation of new departments working with innovation through openness \\
\hline
\end{tabular}

settings and categorize the constructs given to them using a Likert scale in relation to proactive/reactive strategy and cost/inspiration. Second, the discussion will be held to identify the differences in the participant's ratings and to verify the propositions. We thus rate the testability of this theory as high.

\subsubsection{Empirical support}

We identified three studies $[38,39,54]$ highlighting the reduction in development cost (P1) and two studies [37,39] pointed out the reduced time-to-market for software organizations due to the use of OI (P2). It must be mentioned that the reduced time-to-market refers to shorter development time only, and not the marketing. Furthermore, eight studies $[25,37-39,43,50,52,54]$ underpin the proposition on process and product innovation (P3) as a result of Open Innovation. Table 8 shows that P1 and P3 has relatively stronger empirical evidence support compared to P2, P4 and P5. The interview data from studies $[37,39,54]$ suggest that OI helped organizations to reduce time-tomarket (P2), improve innovation capacity and speed (P3), and reduce the development cost (P1).

Henkel et al. [25] and Parida et al. [43] conducted a case study on drivers for embedded systems and a survey in 252 IT organizations, respectively. Both studies conclude that OI needs to put on the "radar screen of the top management" (P5) in order to increase competitiveness, better and faster development releases (P3). In relation to P4, Parida et al. [43] concluded that outside-in OI is positively associated with the organization's radical innovation performance (products new to the world) and incremental innovation (products new to the firm) performance. Henkel et al. [25] also concluded that disruptive innovation challenges managers to look for customers' demands and competitors implementing open models of innovation. However, it raises the question of making new proactive strategies (P5) to respond to disruptive innovation challenge. For example, disruptive innovation may suggest to make a separate organizational unit tasked with this challenge as highlighted in S2.

Morgan et al. [38] presented a study of 13 managers in the software sector in Europe and examined how their perceptions of the benefits and drawbacks of OSS using OI affected their decision to use OI in their organizations. The study shows benefits in terms of increased collaboration, escape from vendor lock-in and encouraging innovation, permit companies to team up with other companies, customers, and universities to overcome certain adoption factors, like technological complexity and facilitate product development.

It should be noted that neither of the aforementioned studies state whether benefits of openness were as a result of a reactive or proactive strategy. Furthermore, the scope of the studies are not limited to tools only, and therefore addressed related to the internal validity threats (Section 4.3.1). The proposed theory is supported or partly supported by the studies mentioned in Table 8. Therefore, we consider the empirical support for this theory to be moderate.

\subsubsection{Explanatory power}

The proposed theory is defined from the abstractions of the synthesis process $[6,36,61]$. The theory highlights the openness for software engineering tools in software organizations in relation to reduced development cost, reduced development time and increased product and process innovation. Furthermore, the theory highlights the motivations of why (conscious management strategy) organizations should become open. Therefore, we consider the explanatory power of this theory as moderate.

\subsubsection{Parsimony}

Parsimony deals with how economically a theory has been constructed in relation to a number of constructs and propositions. The proposed theory is derived from the rich amount of qualitative data extracted from the mapping study (S1), case study (S2) and survey (S3). However, the formulated theory of openness, uses a high level of abstraction, with clear explanation of transitions between theoretical steps. The number of constructs and propositions related to OSS tools were kept low. Therefore, we consider the parsimony of the theory as moderate.

\subsubsection{Generality}

The scope of the proposed theory is limited to software organizations using OSS tools in the internal software development, which makes the generality of the theory low.

\subsubsection{Utility}

From a software organization's perspective, the proposed theory can be utilized for choosing the right level of openness while working with OSS communities. Most software organizations have to work with OSS communities therefore, we see utility of the theory high.

\section{Conclusion and future work}

This paper presents a theory of openness for software engineering tools in software organizations, that helps SIPDOs to understand why and how organizations should capitalize the potential that OSS communities bring to leverage the internal $R \& D$. In relation to the first research goal defined in Section 3.1, the presented theory highlights which type of organizations are involved in embracing openness, and what are the possible challenges (intellectual property rights, complete test coverage, the absence of business strategy etc.) faced by these organizations in relation to openness. Furthermore, this paper highlights some of the potential metrics that could be used to measure innovation as a consequence of openness (see Fig. 2).

However, there are some drivers that need to be understood by SIPDOs to be successful and open at the same time. These drivers entail cost, time-to-market, speed, process and product innovation. Based on the aforementioned objectives, the theory fulfils the second research goal by introducing the level of openness and associated strategies that should be adapted, based on objectives (e.g., cost reduction, reduced development time etc.). Further, it helps positioning an organization with respect to its strategy to act as Laggard, Leverage, Lucrativeness or Leader (see Fig. 5).

Future work includes validating the theory with organizations using OSS tools in their product development to generalize the findings across a broader range of SIPDOs. The validation could possibly discover more reasons for openness depending upon the organizational context. Furthermore, the validation may lead to guidelines for managers depending upon the objectives to achieve using openness. 


\section{Acknowledgment}

This work is funded by the Swedish National Science Foundation Framework Grant for Strategic Research in Information and
Communication Technology, project Synergies (Synthesis of a Software Engineering Framework for Open Innovation through Empirical Research), grant 621-2012-5354.

\section{Appendix A. Survey design}

This appendix presents the survey design details as well as the outcomes. The questionnaire ${ }^{2}$ was divided into two branches, namely contributors and non contributors. The survey questionnaire was distributed among 500 employees working for software-intensive organizations either using Gerrit, Jenkins and Git communities in their development or also, contributing to those communities. The questions were divided into the following categories.

(a) Demographics

(b) Involvement in OI using OSS projects

(c) Operationalization of OI in software engineering

(d) Quality assurance

First, five questions were common for both contributors and non-contributors related to the demographics e.g., organization, working experience with OSS, job title, work responsibilities etc. We received 57 responses including contributors and non contributors to the communities.

We extracted the email list of Jenkins, Gerrit and Git communities from GitHub and distributed the survey among all those contributors and non contributors having organizational affiliations in their email addresses. Contributors refer to all those employees who are contributing source code, documentation, test cases etc. to Jenkins Gerrit and Git. On the other hand, users refer to employees only using OSS software e.g., the use of Jenkins and Gerrit, in the development of their organization's products or services.

The study aimed at responses from the perspective of employees in the context of the nearest organizational unit, using or contributing to OSS communities (Jenkins, Gerrit and Git). The underlying assumption was that the managers may know the overall strategy of the organization, but software developers/testers may only have the local knowledge of their unit. Furthermore, during the pilot survey, respondents highlighted that they could only respond based on their organizational unit since they do not know the OSS contribution strategy of the whole organization, and it may vary from one unit of another unit.

\section{A1. Demographics}

Of the survey respondents $61 \%$ were software developers, followed by managers (14\%), system architects (11\%) and testers (9\%) and CEOs (4\%). Fig. A. 6 represents the number of years of experience of the respondents and Fig. A.7 shows the association of respondents to OSS communities. $68 \%$ of the non contributors have 7 or more years of experience using OSS communities in their respective organizations. On the other hand, 79\% of contributors have 7 or more years of using and contributing to OSS communities. It must be mentioned that survey was initially distributed among Gerrit, Jenkins and Git communities to reach to desired sample population, but it turns out that respondents are working for multiple OSS communities. Therefore, Fig. A.7 shows that a respondent may be associated with multiple OSS communities simultaneously.

\section{A2. Why organizations get involved in OI using OSS?}

Why refers to the factors considered by SIPDOs adopting OI using OSS. OI adoption is not only driven top down, but also bottom up since the majority of the respondents (72\%) in the survey are either tasked by the management to take OI initiatives or volunteered (62\%) to do so. Some respondents (21\%) also see it as a fun way of working with communities as a part of their daily work. The others category (38\%) revealed more factors considered by software organizations before opening up. These factors entail the cost of maintaining forks of OSS code, good discussions forums for exchanging innovative ideas, easier to find a solution to an issue, saves own development cost, create the base ecosystem to innovate and create innovative products that can delivered to the clients, cheaper than in-house development, to motivate/educate engineers in the organization, reduced maintenance cost, continuous development and customer satisfaction.

The survey results also highlighted that organizations see the need to build OSS communities to attract external knowledge into the organization. It is clear from the responses that software organizations make a project open if it is a non-competitive tool or a products that is not a direct source of revenue anymore. The respondents highlighted more contribution strategies (see Fig. A.8): (1) employees working with OSS communities encourage organizations to become open and to gain good reputation in the community, (2) when there are patches involved with the bug correction and licenses that mandate organizations to reveal code, (3) when the contributions are not only specific to the organization and have value for the community as well, (4) competitors' pressure is also one of the main motivations for adopting Open Innovation and acquiring new features in OSS tools such as Jenkins, Gerrit etc.

Fig. A.8 presents the differences between contributors and non contributors in incentives to contribute to OSS communities. The incentives are rated by respondents on a likert scale from less important to very important. The majority of contributors and non contributors agreed in highlighting the importance of getting the latest patches from OSS communities ( $59 \%$ and $57 \%$, respectively). However, there is a difference of opinion between contributors and non contributors when comparing the reputation gain in the community and steering the communities towards organizational interests. $72 \%$ of contributors think that gaining a good reputation is important to steer the community towards their organizational interests. At the same time, only $46 \%$ of non contributors think that is important to gain reputation in the community in order to steer the community towards organizational interests.

Fig. A.9 shows the potential gains reported by contributors and non contributors by involving themselves in OSS communities. Both contributors (57\%) and non contributors (59\%) agreed that the use of OSS communities reduces time to market for the development of products as it frees up

\footnotetext{
${ }^{2}$ http://fileadmin.cs.lth.se/cs/Personal/Hussan_Munir/Surveyform.pdf.
} 

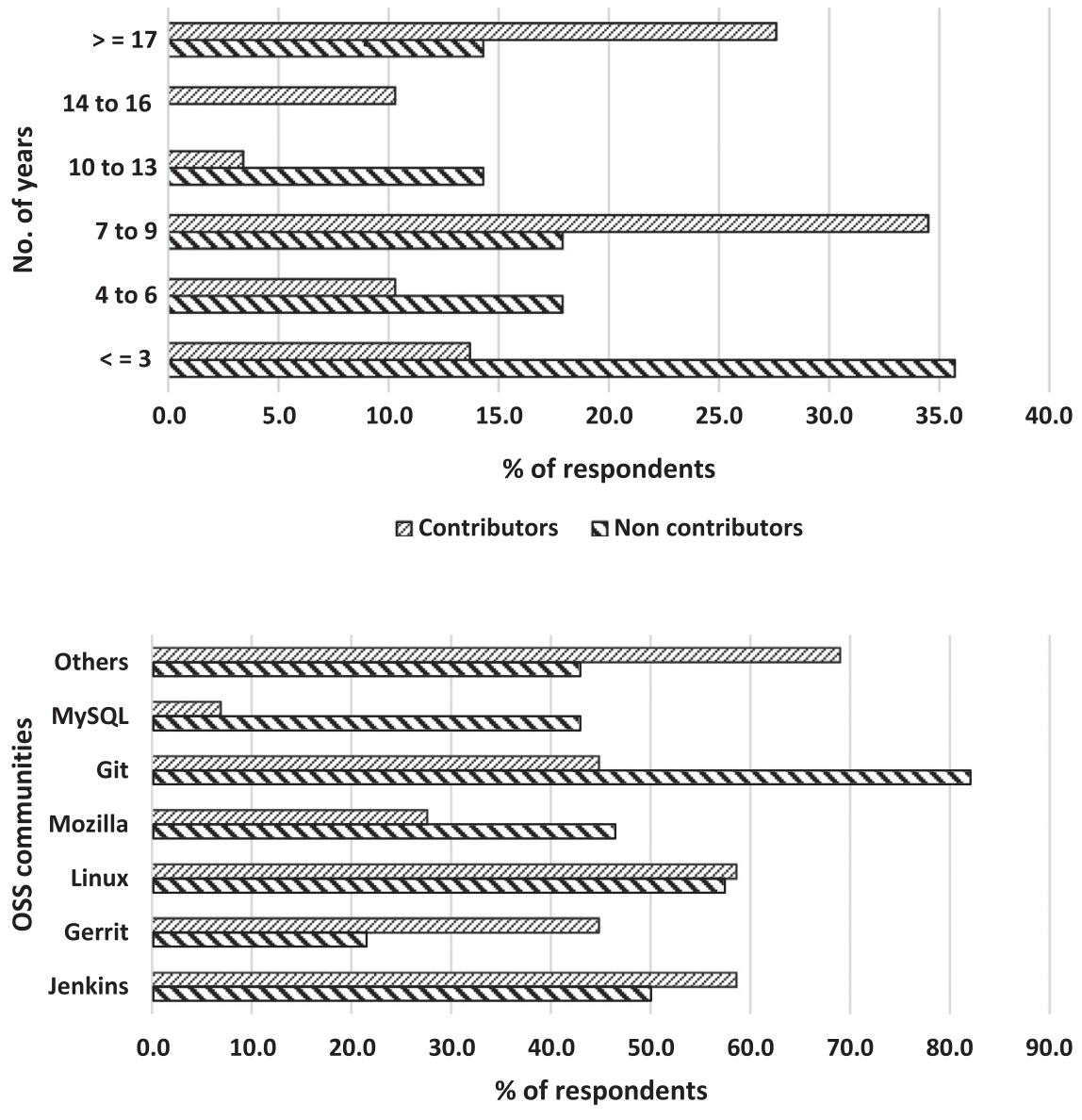

Fig. A.6. Distribution of survey respondents' experience (\%).

Fig. A.7. Distribution of respondents' association with OSS communities (\%).

$\square$ Contributors $\mathbf{N}$ Non contributors

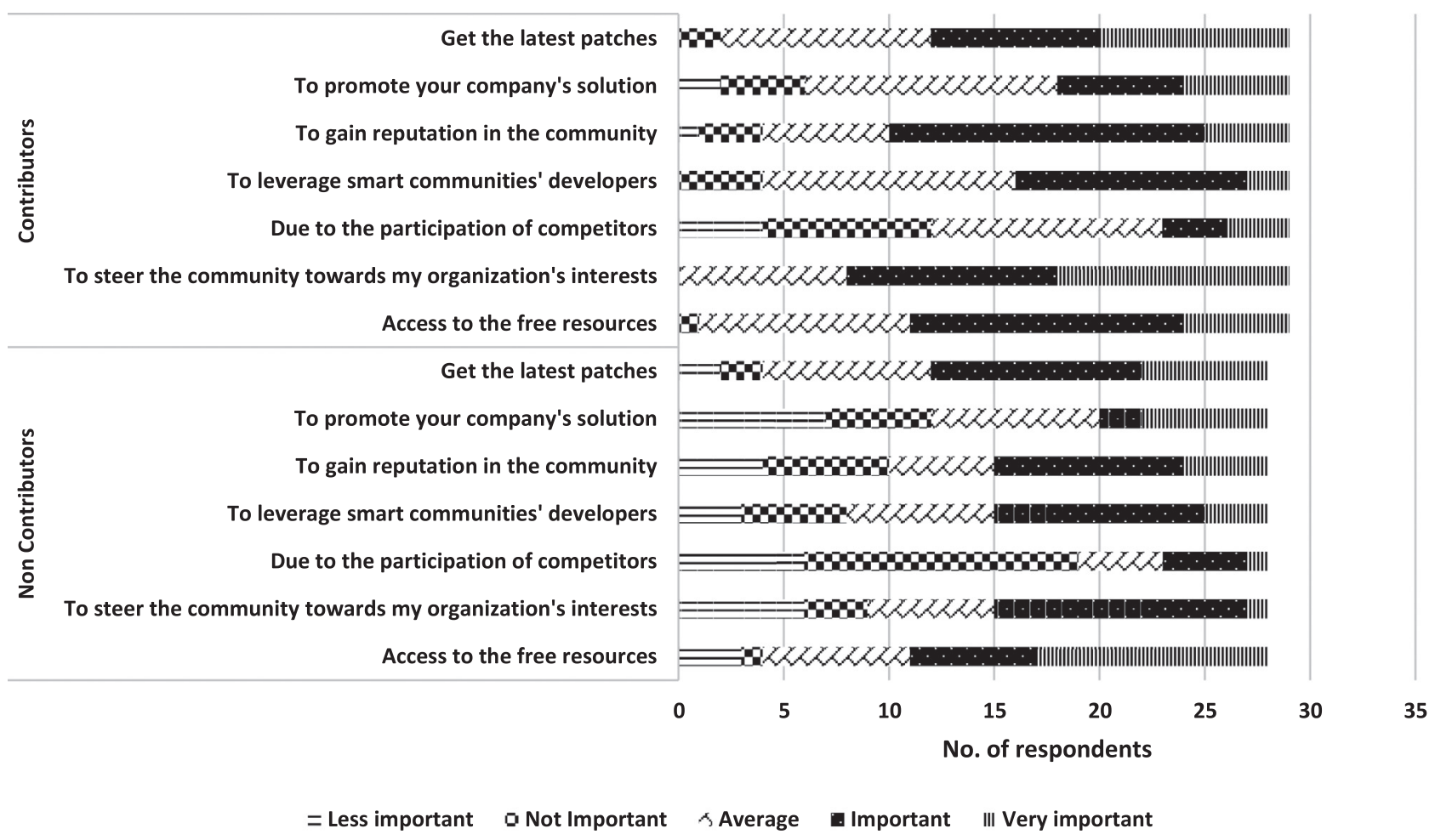

Fig. A.8. Motivating factors to contribute to OSS communities. 


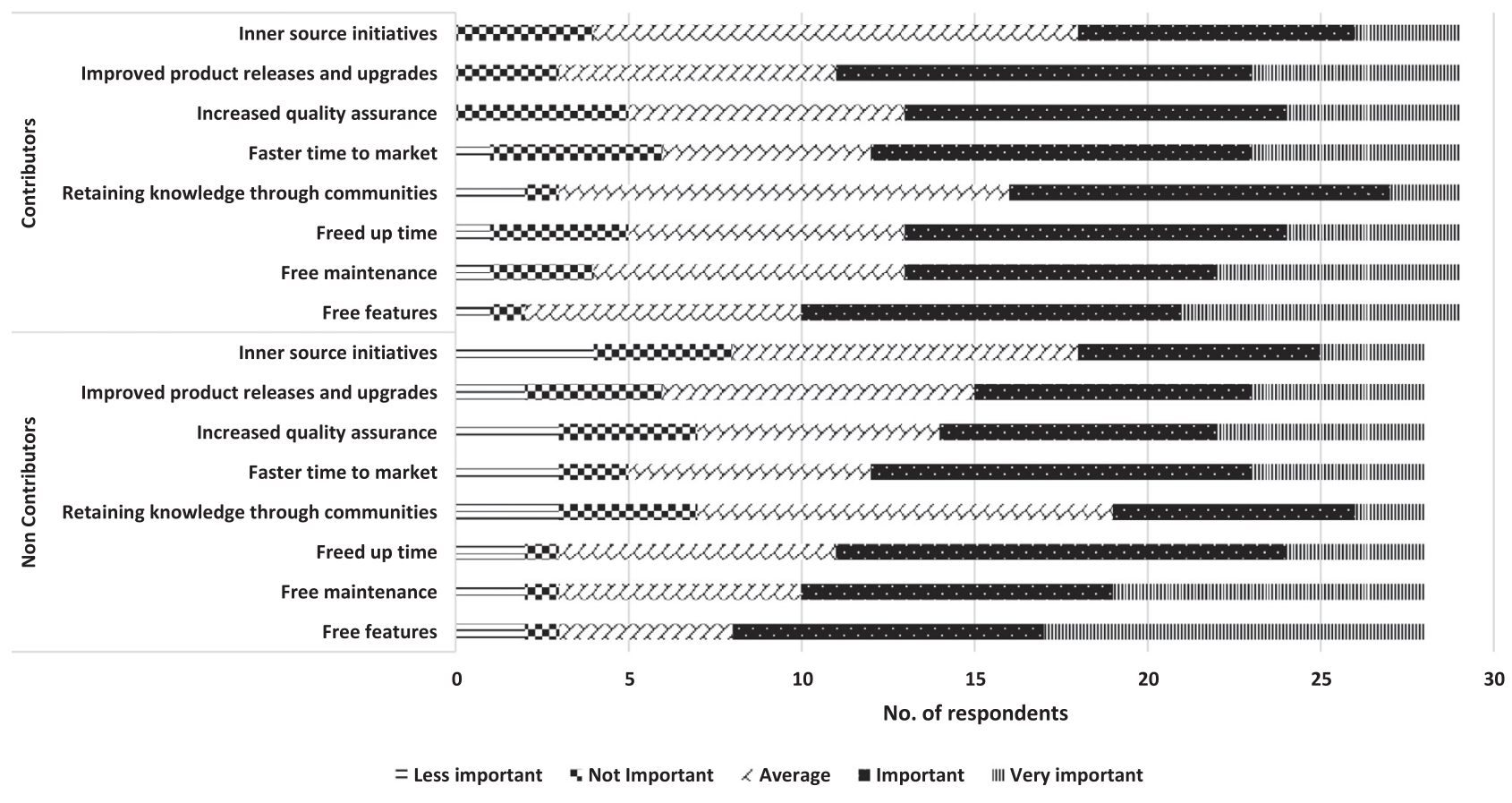

Fig. A.9. Factors gained by companies after contributing to OSS communities.

developer time. However, more contributors $62 \%$ think that using and contributing to OSS communities resulted in improved product releases and upgrades as oppose to $47 \%$ of non contributors.

\section{A3. Operationalization of Open Innovation in software engineering}

Table A.9 shows that $63 \%$ of the respondents spent less than ten hours per week working with OI. At the same time, $31 \%$ respondents in the organizations spent their full time with OI by working with the OSS communities, which indicates that software organizations are realizing the importance of OI to extract and assimilate the external knowledge from communities in the organization's product development.

Regarding contributions to OSS communities, engineers (69\%), middle (55\%) and top level management (52\%) are involved in deciding whether or not to contribute organization's internal source code to OSS communities. However, there is an extra layer of legal managers (45\%) helping organizations to deal with licensing, intellectual property rights and patent infringements.

\section{A4. Quality assurance}

Of the respondents 59\% use OSS tools e.g., JIRA while 31\% use Google's issues tracker for bug reporting. However, bugs are reported to communities by email (28\%) and weekly/monthly meetings (21\%) among the contributors. One possible explanation of reporting bugs through email or meetings is that those bug could be relevant to the organizations only and contributing it to the community would not give any value.

Among the respondents $45 \%$ reveal more than $75 \%$ of their organization's source code to the communities. A plausible explanation of this could be that the source code is not seen as a competitive advantage, or to build a community around the non competitive tools such as Jenkins or Gerrit. On the other hand, $52 \%$ of the respondents choose to reveal less than $25 \%$ of the code to the communities, due to the risk of losing the intellectual property rights or due to lack of understanding of the OSS culture in the organization.

Out of the respondents $79 \%$ mentioned that bug fixing is prioritized based on the needs of organizations. It was also confirmed by $\mathrm{S} 2$ that if a bug is a make or break for the organization's development process then the organization choose to fix it. Otherwise, bugs are pushed into the Google's issue tracker for someone else to fix it. Furthermore, $38 \%$ of the respondents think the bugs are prioritized based on the communities needs as well in order to gain good reputation in the community.

Table A.9

Time spent on OI.

\begin{tabular}{ll}
\hline Time spent & $\%$ \\
\hline Less than $5 \mathrm{~h}$ & 49 \\
$6-10 \mathrm{~h}$ & 14 \\
$10-15 \mathrm{~h}$ & 3 \\
$16-20 \mathrm{~h}$ & 0 \\
$21-25 \mathrm{~h}$ & 3 \\
Full time & 31 \\
\hline
\end{tabular}


Appendix B. Who - Organizations involved in Open Innovation

Table B.10

Non contributors.

\begin{tabular}{|c|c|c|c|}
\hline Organization names & Product type & People:(Size, Roles, experience) & Oss Tools \\
\hline Perten Instruments $\mathrm{AB}$ & $\begin{array}{l}\text { Mechanical or Industrial Engineering Web based } \\
\text { monitoring and analysis applications }\end{array}$ & $\begin{array}{l}\text { 51-200 employees, Present in over } 100 \\
\text { countries System architect, Software } \\
\text { developer 7-9 years }\end{array}$ & $\begin{array}{l}\text { Linux, Git, jQuery, knockout, bootstrap, jcanvas, } \\
\text { requirejs.net, Jenkins, Mozilla Firefox }\end{array}$ \\
\hline Sysart, Finland & Computer Software & $\begin{array}{l}51-200 \text { employees, Software } \\
\text { development, System architect, 4-6 } \\
\text { years }\end{array}$ & $\begin{array}{l}\text { Jenkins, Gerrit, Linux, Mozilla Firefox, Git, } \\
\text { MySQL, nginx, openjdk, apache httpd, } \\
\text { postgresql }\end{array}$ \\
\hline Vnomics, Inc. & Transportation & $\begin{array}{l}\text { 51-200 employees, Software developer, } \\
7-9 \text { years }\end{array}$ & $\begin{array}{l}\text { Jenkins, Linux, Mozilla Firefox, Git, MySQL, } \\
\text { Mercurial, Java }\end{array}$ \\
\hline $\begin{array}{l}\text { Henan University, } \\
\text { China }\end{array}$ & Academics & $\begin{array}{l}12,500 \text { students, Software } \\
\text { developer, }<17 \text { years }\end{array}$ & Jenkins;Linux;Mozilla Firefox;Git;ant, libreoffice \\
\hline $\begin{array}{l}\text { Polytechinc of Milan, } \\
\text { Italy }\end{array}$ & Academics & $\begin{array}{l}40,000 \text { students, Manager, } \\
\text { Teacher, }<17 \text { more }\end{array}$ & Mozilla Firefox;Git \\
\hline Spirosoft & $\begin{array}{l}\text { Expertise in both embedded systems and desktop } \\
\text { computing. }\end{array}$ & $\begin{array}{l}\text { 1-10 employees, Software tester, Write } \\
\text { testcases, Execution, }>3\end{array}$ & Mozilla Firefox, Git \\
\hline Datenc & Cloud computing Cloud Solutions Data storage solutions & $\begin{array}{l}\text { 1-10 employees, Software Designing, } \\
\text { Development and Management, System } \\
\text { Architect }>3\end{array}$ & Linux, MySQL \\
\hline GRID Systems Pakistan & $\begin{array}{l}\text { E-commerce services, Software Development and } \\
\text { teamwork. Clinic Software }\end{array}$ & $\begin{array}{l}\text { 1-10 employees, Software Designing, } \\
\text { Development and Management, } \\
\text { Software tester } 4-6 \text { years }\end{array}$ & Linux, MySQL \\
\hline OSSE, USA & Mechanical or Industrial Engineering & $\begin{array}{l}\text { 51-200 employees, Software developer, } \\
7-9 \text { years }\end{array}$ & Git \\
\hline Meltwater & Information Technology and Services & $\begin{array}{l}\text { 1001-5000 employees, Software } \\
\text { developer, NA }\end{array}$ & Jenkins, Linux, Git, MySQL \\
\hline Agilecrm and Hyd & Customer Relationship Management system & $\begin{array}{l}\text { 51-200 employees, Software tester, 4-6 } \\
\text { years }\end{array}$ & Linux, Mozilla Firefox, Git \\
\hline $\begin{array}{l}\text { XLN Audio AB, } \\
\text { Stockholm }\end{array}$ & Music software & $\begin{array}{l}\text { 11-50 employees, software developer, } \\
\text { system architect, 10-13 years }\end{array}$ & Git, JUCE, juce, MySQL \\
\hline Confiz, Pakistan & $\begin{array}{l}\text { Specialties Portal Applications, Mobility, Cloud } \\
\text { Computing, Content Management, Cross Platform } \\
\text { Frameworks, Android applications }\end{array}$ & $\begin{array}{l}\text { 201-500 employees, Principal Software } \\
\text { Engineer, Software tester, Team leader, } \\
\text { 7-9 years }\end{array}$ & $\begin{array}{l}\text { Linux, Git, MySQL Jenkins, Mozilla Firefox, Git, } \\
\text { MySQL }\end{array}$ \\
\hline $\begin{array}{l}\text { Follow-up System, } \\
\text { Stockholm }\end{array}$ & Information Technology and Services & $\begin{array}{l}\text { 11-50 employees, Software developer, } \\
>\quad 3 \text { years }\end{array}$ & Jenkins, Linux, Mozilla Firefox, Git, MySQL \\
\hline $\begin{array}{l}\text { Saudi Telecom } \\
\text { organization }\end{array}$ & Telecommunications sector & $\begin{array}{l}10,001+\text { employees, System architect, } \\
10-13 \text { years }\end{array}$ & Jenkins, Gerrit, Git, MySQL \\
\hline
\end{tabular}


Table B.11

Contributors.

\begin{tabular}{|c|c|c|c|}
\hline Organization names & Product type & People:(Size, Roles, experience) & OSS Tools \\
\hline Ericsson & Telecommunications Industry & $\begin{array}{l}\text { More than } 100,000 \text { employee, More than } 37,000 \\
\text { patents, } 40 \% \text { of mobile calls are made through } \\
\text { our systems } 180 \text { countries, Manager, Software } \\
\text { developer, }<10 \text { years }\end{array}$ & $\begin{array}{l}\text { Jenkins, Gerrit, Linux, Git, } \\
\text { Sonarqube, Casandra }\end{array}$ \\
\hline SAP & Enterprise application software & $\begin{array}{l}10,001+\text { employees, Software developer, 7-9 } \\
\text { years }\end{array}$ & $\begin{array}{l}\text { Jenkins, Gerrit, Linux, Git, BUILD, } \\
\text { Eclipse }\end{array}$ \\
\hline Google, USA & $\begin{array}{l}\text { Specialties include search, ads, mobile, android, online } \\
\text { video, apps, machine learning, virtual reality }\end{array}$ & $\begin{array}{l}\text { 10,001+ employees, Software Engineer, 7-9 } \\
\text { years }\end{array}$ & Gerrit, Linux, Git \\
\hline Axis, Sweden & $\begin{array}{l}\text { Specialties include Network video, IP Video surveillance, } \\
\text { Security camera, CCTV, IP camera Industry Computer } \\
\text { Networking }\end{array}$ & $\begin{array}{l}\text { 1001-5000 employees, over } 80,000 \text { partners, } \\
\text { Software developer }<17 \text { years }\end{array}$ & Jenkins, Gerrit, Linux \\
\hline Sony Mobile Sweden & & $\begin{array}{l}10,001+\text { employees Software developer, } \\
\text { Manager, System architect }<7 \text { years }\end{array}$ & $\begin{array}{l}\text { Jenkins, Gerrit, Linux, Mozilla } \\
\text { Firefox, Git, Jgit, eclipse, repo, } \\
\text { gitlab, android, Jgit, GitLab, Repo, } \\
\text { Chromium, mainly Android }\end{array}$ \\
\hline Mozilla Vancouver & $\begin{array}{l}\text { Specialties include browser, internet, software, mobile, } \\
\text { web apps, OS, identity }\end{array}$ & $\begin{array}{l}501-1000 \text { employees, Software developer } \\
\text { testing, }<17 \text { or more }\end{array}$ & Mozilla Firefox, mercurial \\
\hline Intel Lund & $\begin{array}{l}\text { Specialties includes semiconductor design and } \\
\text { manufacturing }\end{array}$ & $\begin{array}{l}10,001+\text { employees, } 63 \text { countries, Manager } \\
\text { Managing a team of SW engineers and managing } \\
\text { the Intel Lund site, Manager }<17 \text { years }\end{array}$ & Linux \\
\hline Thales UK & $\begin{array}{l}\text { Specialties include Aerospace, Defence, Security, Space, } \\
\text { Transportation, Cybersecurity }\end{array}$ & $\begin{array}{l}\text { 10,001 + employees, Software developer support } \\
\text { (installation/configuration) of all software/ } \\
\text { system development tools, linux admin, virtual } \\
\text { data center admin, 14-16 years }\end{array}$ & Git \\
\hline ESO, Germany & $\begin{array}{l}\text { Specialties include astronomical research technology and } \\
\text { producing scientific libraries under GPL }\end{array}$ & $\begin{array}{l}501-1000 \text { employees, Software developer } \\
\text { Scientific software development and } \\
\text { maintenance, regression testing, }<14 \text { years, }\end{array}$ & $\begin{array}{l}\text { Junit, Selenium, Also customised } \\
\text { tools to interface with } \mathrm{C} / \mathrm{C}++ \text { and } \\
\text { Python code. }\end{array}$ \\
\hline $\begin{array}{l}\text { SmartKompare.com } \\
\text { Dhaka }\end{array}$ & $\begin{array}{l}\text { Specialties includes Financial Technology, Information, } \\
\text { Comparison }\end{array}$ & $\begin{array}{l}\text { 11-50 employees, CEO Managing team, leading } \\
\text { tech team, We develop modules etc },>3 \text { years }\end{array}$ & Drupal \\
\hline Red Hat Spain & $\begin{array}{l}\text { Specialties in cloud computing, hybrid cloud } \\
\text { management, Linux, open source, virtualization, storage, } \\
\text { middleware, containers, mobile, OpenStack }\end{array}$ & $\begin{array}{l}\text { 5001-10,000 employees, Continuous Integration } \\
\text { Engineer Design, }<17 \text { years }\end{array}$ & $\begin{array}{l}\text { Jenkins, Gerrit, Linux, Git, MySQL, } \\
\text { Fedora, openstack, gnome, kde, } \\
\text { gimp }\end{array}$ \\
\hline $\begin{array}{l}\text { Flownative Gmbh, } \\
\text { Germany }\end{array}$ & $\begin{array}{l}\text { Flownative helps organisations creating first-class Neos } \\
\text { websites and sophisticated Flow applications. }\end{array}$ & $\begin{array}{l}\text { 1-5 employees, Developer and CEO Software } \\
\text { development and testing, }>3 \text { years }\end{array}$ & $\begin{array}{l}\text { Neos, Doctrine \& other (mostly PHP) } \\
\text { projects }\end{array}$ \\
\hline $\begin{array}{l}\text { A National Laboratory, } \\
\text { USA }\end{array}$ & Research and development & Software developer, $<17$ years & $\begin{array}{l}\text { Jenkins, Linux, Mozilla Firefox, } \\
\text { Boost } \mathrm{C}++\end{array}$ \\
\hline Garmin & $\begin{array}{l}\text { Specialties include Consumer Electronics, Worldwide } \\
\text { leader in navigation \& communication products, } \\
\text { Products in aviation, marine, fitness, outdoor, \& } \\
\text { automotive products }\end{array}$ & $\begin{array}{l}\text { 10,001 + employees, Software developer Lead a } \\
\text { team, 7-9 years }\end{array}$ & Jenkins, Gerrit, Linux, Git \\
\hline $\begin{array}{l}\text { Qvantel, Karlslrona } \\
\text { Sweden }\end{array}$ & $\begin{array}{l}\text { Specialties include Cloud based Business Support } \\
\text { Systems (BSS), Software Development Services, Offshore } \\
\text { Software Development for small/mid size software } \\
\text { vendors, Business Process Management (BPM) Services }\end{array}$ & $\begin{array}{l}201-500 \text { employees, Auto execution of } \\
\text { integration test, Build failure/Success, Regression } \\
\text { testing, 4-6 years }\end{array}$ & $\begin{array}{l}\text { Jenkins, Linux, Mozilla Firefox, Git, } \\
\text { Bigdata, Stash }\end{array}$ \\
\hline Confiz & $\begin{array}{l}\text { Specialties include Portal Applications, Mobility, Cloud } \\
\text { Computing, Content Management Touch, Quality } \\
\text { Engineering, .NET Frameworks, JS Frameworks, } \\
\text { Windows 8, Android applications }\end{array}$ & $\begin{array}{l}\text { 201-500 employees, Software developer, Project } \\
\text { documentation, Requirement Analysis and writes } \\
\text { Automation Script, 7-9 years }\end{array}$ & $\begin{array}{l}\text { Jenkins, Linux, Git, MySQL Jenkins, } \\
\text { Mozilla Firefox, Git, MySQL }\end{array}$ \\
\hline Yatta Solutions Germany & $\begin{array}{l}\text { Specialties include Eclipse, software development, } \\
\text { software architecture, software engineering, UML }\end{array}$ & 11-50 employees, Software developer, 7-9 years & Eclipse \\
\hline
\end{tabular}


Appendix C. Example of raw data collected from S1, S2 and S3

Table C.12

Selected raw data from S1, S2, and S3. Please note that it is only a small part of raw data collected from the three studies to show an example.

\begin{tabular}{|c|c|c|c|}
\hline Facets & $\mathrm{S} 1$ & $\mathrm{~S} 2$ & S3 \\
\hline $\begin{array}{l}\text { Organizations using OSS } \\
\text { tools e.g., Jenkins, } \\
\text { Gerrit, Git }\end{array}$ & Nokia, IBM, RdHat, HP & $\begin{array}{l}\text { Sony, Google, Ericsson, HP, SAP, Intel, Latombe, } \\
\text { BlackBuild, Redhat, Codeaurora, Quelltextlich }\end{array}$ & Perten, Sony, Intel, XLN Audio AB, Confiz \\
\hline $\begin{array}{l}\text { Strategies used by SIPDOs } \\
\text { for openness }\end{array}$ & $\begin{array}{l}\text { Accessing and extending the resource-base } \\
\text { of the firm, Aligning the firm's strategy } \\
\text { with the community, Integrating and } \\
\text { sharing results, Selective revealing }\end{array}$ & $\begin{array}{l}\text { Difficult to keep up with the community's pace } \\
\text { due to lack of resources, More patching as result } \\
\text { of different direction than the community, Access } \\
\text { to pragmatic software development workforce, } \\
\text { To influence or steer community towards } \\
\text { company's business model }\end{array}$ & $\begin{array}{l}\text { To build a community around the project, When } \\
\text { the product looses competitiveness, When the } \\
\text { product is the main source of revenue, Because } \\
\text { your competitors are making their projects open } \\
\text { source, Non competitive tools only }\end{array}$ \\
\hline $\begin{array}{l}\text { Factors considered by } \\
\text { software organization } \\
\text { for openness }\end{array}$ & $\begin{array}{l}\text { Knowledge building and exchange, } \\
\text { Platform and software reuse, Innovation } \\
\text { support, Time to market, cost, } \\
\text { maintenance Culture change }\end{array}$ & $\begin{array}{l}\text { To move from Windows to Linux, Proprietary } \\
\text { solutions to OSS solutions, Ease off the complex } \\
\text { integration and building process, }\end{array}$ & $\begin{array}{l}\text { Fun way of working, Tasked by management, cost } \\
\text { of maintaining forks of OSS code, good discussions } \\
\text { forums for exchanging innovative ideas, Influence } \\
\text { and reputation }\end{array}$ \\
\hline $\begin{array}{l}\text { Challenges faced by } \\
\text { organizations to adopt OI }\end{array}$ & $\begin{array}{l}\text { Business strategy (i.e unclear contribution } \\
\text { strategy), Strategic OI barriers (i.e. lack of } \\
\text { expertise), Governance (i.e. giving up } \\
\text { control) }\end{array}$ & $\begin{array}{l}\text { Legal issues, Intellectual property rights, Lack of } \\
\text { OSS culture, lack of understanding, Risk of losing } \\
\text { competitive advantage }\end{array}$ & $\begin{array}{l}\text { Time, Protecting intellectual property Dependency } \\
\text { towards an open source community for support, It } \\
\text { steal's focus from our main tasks, I guess the } \\
\text { potential has not been identified by the managers., } \\
\text { End user requirements are highest priority, } \\
\text { Business secrets/policies, Lack of resources, Lack of } \\
\text { developer time }\end{array}$ \\
\hline
\end{tabular}

\section{Appendix D. Rigor and relevance criteria}

D1. Rigor

\section{Context(C)}

(a) Strong description: The context is described to the extent where it becomes comparable to other settings [29]. In particular, we emphasized subject type (graduate, undergraduate, professionals, researcher), development experience, development methodology, duration of the observation. If all these aforementioned factors are highlighted, then C is evaluated to 1 .

(b) Medium description: If any of the above mentioned factors is missing in the study, then $\mathrm{C}$ is evaluated to 0.5.

(c) Weak description: If no description of context is provided in the study, then $\mathrm{C}$ is evaluated to 0 .

\section{Design (D)}

(a) Strong description: The research design is described to the extent where it becomes transparent and detailed enough for the reader to understand the design [29]. To be specific, if the study underlined the outcome variables, measurement criteria, treatments, number of subjects , and sampling, then $\mathrm{D}$ is evaluated to 1 .

(b) Medium description: If a study is missing out on any of the factors related to design and data collection is missing (see above), then D evaluates to 0.5 .

(c)Weak description: If no design description is provided at all then, $\mathrm{D}$ is evaluated to 0 .

\section{Validity threats (V)}

(a) Strong description: If different types of validity (i.e. internal, external, conclusion and construct validity) are evaluated and reflected upon then, $\mathrm{V}$ is evaluated to 1 .

(b) Medium description: If a study only highlights the subset of the relevant threat categories then, $\mathrm{V}$ is evaluated to 0.5

(c) Weak description: If a study is missing out on validity discussion completely, then $\mathrm{V}$ is evaluated to 0.

\section{D2. Relevance}

\section{Users/Subjects (U)}

(a) Contribute to relevance: If the subjects used in the study are from industry (professionals) then, $\mathrm{U}$ is evaluated to 1 for industry.

(b) Partially contribute to relevance: The subjects are partially representative, i.e. they are master(Msc.) or graduated students then, $\mathrm{U}$ is evaluated to 0.5

(c) Does not contribute to relevance: If the subjects are bachelor/undergrad students or the information is missing then, $\mathrm{U}$ is evaluated to 0 . 
(a)Contribute to relevance: If an industrial size application is used in the study then, $S$ is evaluated to 1.

(b) Does not contribute to relevance: The application is down-scaled or a toy example hence, $S$ is evaluated to 0 .

\section{Research Methodology (RM)}

(a) Contribute to relevance: The chosen research methodology is suitable to scrutinize real world contexts and situations with relevance for practitioners (action research, case study, industry interviews, experiment investigating a real situation, and surveys/interviews). If study belongs to any of the aforementioned research methodologies then, RM is evaluated to 1 .

(b) Does not contribute to relevance: If a Study is using Lab experiment (human subjects/software) or missing information then, RM is evaluated to 0 .

\section{Context $(C)$}

(a) Contribute to relevance: If a study is executed in a setting that matches real industrial usage (industrial setting) then, C is evaluated to 1 . (b) Does not contribute to relevance: If a study is investigated under artificial setting (e.g. lab) or others that do not represent a context matching real world situations, or not reported then, $\mathrm{C}$ is evaluated to 0 .

\section{References}

[1] V.R. Basili, F. Shull, F. Lanubile, Building knowledge through families of experiments, IEEE Trans. Softw. Eng. 25 (4) (1999) 456-473.

[2] E. Bjarnason, K. Smolander, E. Engström, P. Runeson, A theory of distances in software engineering, Inf. Softw. Technol. 70 (2016) 204-219.

[3] J. Bosch, Achieving simplicity with the three-layer product model, Computer 46 (11) (2013) 34-39.

[4] J. Bosch, Speed, data, and ecosystems: the future of software engineering, IEEE Softw. 33 (1) (2016) 82-88.

[5] S. Brad, M. Fulea, B. Mocan, A. Duca, E. Brad, Software platform for supporting open innovation, IEEE International Conference on Automation, Quality and Testing, Robotics, 2008. AQTR Vol. 3 IEEE, 2008, pp. 224-229.

[6] J.M. Carroll, P.A. Swatman, Structured-case: a methodological framework for building theory in information systems research, Eur. J. Inf. Syst. 9 (4) (2000) 235-242.

[7] H. Chesbrough, Why companies should have open business models, MIT Sloan Manag. Rev. 48 (2) (2012)

[8] H. Chesbrough, W. Vanhaverbeke, J. West (Eds.), New Frontiers in Open Innovation, Oxford University Press, 2014.

[9] K. Conboy, L. Morgan, Beyond the customer: opening the agile systems development process, Inf. Softw. Technol. 53 (5) (2011) 535-542.

[10] D.S. Cruzes, T. Dybå, Research synthesis in software engineering: a tertiary study, Inf. Softw. Technol. 53 (5) (2011) 440-455.

[11] D.S. Cruzes, T. Dybå, P. Runeson, M. Höst, Case studies synthesis: a thematic, crosscase, and narrative synthesis worked example, Empir. Softw. Eng. (2014).

[12] L. Dahlander, D.M. Gann, How open is innovation? Res. Policy 39 (6) (2010) 699-709.

[13] L. Dahlander, M. Magnusson, How do firms make use of open source communities? Long Range Plann. 41 (6) (2008) 629-649.

[14] L. Dahlander, M.G. Magnusson, Relationships between open source software companies and communities: observations from nordic firms, Res. Policy 34 (4) (2005) 481-493.

[15] L. Dahlander, M.W. Wallin, A man on the inside: unlocking communities as complementary assets, Res. Policy 35 (8) (2006) 1243-1259.

[16] P.M. Di Gangi, M. Wasko, Steal my idea organizational adoption of user innovations from a user innovation community: a case study of dell ideastorm, Decis. Support Syst. 48 (2009) 303-312.

[17] W. Ebner, J. Leimeister, H. Krcmar, Community engineering for innovations: the ideas competition as a method to nurture a virtual community for innovations, R\&D Manag. 39 (September 4) (2009) 342-356.

[18] H. Edison, N. Bin Ali, R. Torkar, Towards innovation measurement in the software industry, J. Syst. Softw. 86 (5) (2013) 1390-1407.

[19] K. El-Emam, D. Hoaglin, P. Jones, B. Kitchenham, S. Pfleeger, L. Pickard, J. Rosenberg, Preliminary Guidelines for Empirical Research in Software Engineering, National Research Council of Canada, 2001.

[20] A. Endres, H.D. Rombach, A Handbook of Software and Systems Engineering: Empirical Observations, Laws, and Theories, Pearson Education, 2003.

[21] E. Enkel, O. Gassmann, H. Chesbrough, Open R\&D and open innovation: exploring the phenomenon, R\&D Manag. 39 (4) (2009) 311-316.

[22] F.D. Erickson, Qualitative methods in research on teaching, in: M.C. Wittrock (Ed.), Handbook of Research on Teaching, 3rd, MacMillan, New York, NY, 1986, pp. $119-161$.

[23] O. Gassmann, E. Enkel, Towards a theory of open innovation: three core process archetypes, (2004).

[24] J. Henkel, Selective revealing in open innovation processes: the case of embedded Linux, Res. Policy 35 (7) (2006) 953-969.

[25] J. Henkel, S. Schöberl, O. Alexy, The emergence of openness: how and why firms adopt selective revealing in open innovation, Res. Policy (2013).
[26] J.D. Herbsleb, A. Mockus, Formulation and preliminary test of an empirical theory of coordination in software engineering, ACM SIGSOFT Software Engineering Notes, 28 ACM, 2003. 138-137

[27] E.K. Huizingh, Open innovation: state of the art and future perspectives, Technovation 31 (1) (2011) 2-9.

[28] S. Husig, S. Kohn, Open CAI 2.0 - computer aided innovation in the era of open innovation and Web 2.0, Comput. Ind. 62 (4) (2011) 407-413.

[29] M. Ivarsson, T. Gorschek, A method for evaluating rigor and industrial relevance of technology evaluations, Empir. Softw. Eng. 16 (3) (2011) 365-395.

[30] M.O. Laine, Using knowledge from end-users online for innovations: effects of software firm types, 114 LNBIP, Cambridge, MA, United states, 2012, pp. 70-78.

[31] U. Lichtenthaler, H. Ernst, Opening up the innovation process: the role of technology aggressiveness, R\&d Manag. 39 (1) (2009) 38-54.

[32] J. Linåker, H. Munir, P. Runeson, B. Regnell, C. Schrewelius, A survey on the perception of innovation in a large product-focused software organization, 6th International Conference on Software Business - ICSOB, (2015).

[33] J. Linåker, H. Munir, K. Wnuk, C. Mols, Motivating the contributions: an open innovation perspective on what to share as open source software, J. Syst. Softw. 135 (Supplement C) (2018) 17-36, http://dx.doi.org/10.1016/j.jss.2017.09.032.

[34] F.v.d. Linden, B. Lundell, P. Marttiin, Commodification of industrial software: a case for open source, IEEE Softw. 26 (4) (2009) 77-83.

[35] S. Merriam, What can you tell from an $\mathrm{n}$ of 1 ?: issues of validity and reliability in qualitative research, PAACE J. Lifelong Learn. 4 (1995) 50-60.

[36] R.K. Merton, Social Theory and Social Structure, Simon and Schuster, 1968.

[37] L. Morgan, J. Feller, P. Finnegan, Exploring inner source as a form of intra-organisational open innovation, AISeL, 2011.

[38] L. Morgan, P. Finnegan, Open innovation in secondary software firms: an exploration of managers perceptions of open source software, Database Adv.Inf.Syst. 41 (1) (2010) 76-95.

[39] H. Munir, J. Linåker, K. Wnuk, P. Runeson, B. Regnell, Open innovation using open source tools: a case study at Sony mobile, Empir. Softw. Eng. (2017) 1-38.

[40] H. Munir, M. Moayyed, K. Petersen, Considering rigor and relevance when evaluating test driven development: a systematic review, Inf. Softw. Technol. 56 (4) (2014) 375-394.

[41] H. Munir, P. Runeson, Software testing in open innovation: an exploratory case study of the acceptance test harness for Jenkins, ICSSP 2015, ACM, New York, NY, USA, 2015, pp. 187-191.

[42] H. Munir, K. Wnuk, P. Runeson, Open innovation in software engineering: a systematic mapping study, Empir. Softw. Eng. (2015).

[43] V. Parida, M. Westerberg, J. Frishammar, Effect of open innovation practices on SMEs innovative performance: an empirical study, ICSB World Conference Proceedings, International Council for Small business (ICSB), 2011, p. 1.

[44] J. Popay, H. Roberts, A. Sowden, M. Petticrew, L. Arai, M. Rodgers, N. Britten, K. Roen, S. Duffy, Guidance on the conduct of narrative synthesis in systematic reviews, A product from the ESRC methods programme Version 1 (2006) b92.

[45] C. Robson, K. McCartan, Real World Research, John Wiley \& Sons, 2016.

[46] R. Rohrbeck, K. Holzle, H. Gemunden, Opening up for competitive advantage - how Deutsche Telekom creates an open innovation ecosystem, R \& D Manag. 39 (4) (2009) 420-430.

[47] P. Runeson, M. Höst, A. Rainer, B. Regnell, Case Study Research in Software Engineering - Guidelines and Examples, Wiley, 2012.

[48] C. Sauer, D.R. Jeffery, L. Land, P. Yetton, The effectiveness of software development technical reviews: a behaviorally motivated program of research, IEEE Trans. Softw. Eng. 26 (1) (2000) 1-14.

[49] W.R. Shadish, T.D. Cook, D.T. Campbell, Experimental and Quasi-Experimental Designs for Generalized Causal Inference, Wadsworth Cengage Learning, 2002.

[50] L. Singer, N. Seyff, S.A. Fricker, Online social networks as a catalyst for softwar and IT innovation, 4th International Workshop on Social Software Engineering, SSE'11 - Proceedings of the 4th International Workshop on Social Software 
Engineering, (2011), pp. 1-5

[51] D.I. Sjøberg, T. Dybå, B.C. Anda, J.E. Hannay, Building theories in software engineering, Guide to Advanced Empirical Software Engineering, Springer, 2008, pp. 312-336.

[52] W. Stam, When does community participation enhance the performance of open source software companies? Res. Policy 38 (8) (2009) 1288-1299.

[53] K.-J. Stol, M. Goedicke, I. Jacobson, Introduction to the special sectiongeneral theories of software engineering: new advances and implications for research, Inf. Softw. Technol. 70 (2016) 176-180.

[54] M. Stuermer, S. Spaeth, G. Von Krogh, Extending private-collective innovation: a case study, R\&D Manag. 39 (2) (2009) 170-191.

[55] W.F. Tichy, Should computer scientists experiment more? Computer 31 (5) (1998) $32-40$.

[56] G. Von Krogh, S. Spaeth, K.R. Lakhani, Community, joining, and specialization in open source software innovation: a case study, Res. Policy 32 (7) (2003) $1217-1241$.

[57] J. West, S. Gallagher, Challenges of open innovation: the paradox of firm investment in open-source software, R \& D Manag. 36 (3) (2006) 319-331.

[58] J. West, S. Gallagher, Patterns of open innovation in open source software, Open Innovation: Researching a New Paradigm, 235(11) (2006).

[59] J. Whitehurst, The Open Organization, Harvard Business Review Press, 2015.

[60] K. Wnuk, D. Pfahl, D. Callele, E. Karlsson, How can open source software development help requirements management gain the potential of open innovation: an exploratory study, (2012), pp. 271-279. Piscataway, NJ, USA

[61] R.K. Yin, Case study research: design and methods, Applied social research methods series, Thousand Oaks, CA: Sage Publications, Inc. Afacan, Y., \& Erbug, C.(2009). An interdisciplinary heuristic evaluation method for universal building design. Journal of Applied Ergonomics 40 (2003) 731-744.

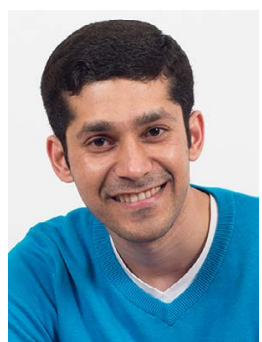

Hussan Munir is a PHD student at Lund University. He received his Master of Science in Software Engineering from Blekinge Institute of Technology. Thereafter, he worked as a software engineer at Ericsson $\mathrm{AB}$ with the main focus on automated testing. His current research focus encompasses Open Innovation for Software Engineering in collaboration with software-intensive product development organizations.

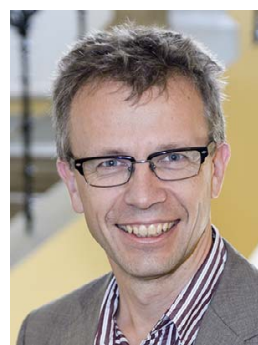

Dr. Per Runeson is a professor of software engineering at Lund University, Sweden, head of the Department of Computer Science, and the leader of its Software Engineering Research Group (SERG) and the Industrial Excellence Center on Embedded Applications Software Engineering (EASE). His research interests include em pirical research on software development and management methods, in particular for software testing and open innovation, and cross disciplinary topics on the digital society. He has contributed significantly to software engineering research methodology by the books on case studies and experimentation in software engineering. He serves on the editorial boards of Empirical Software Engineering and Software Testing, Verification and Reliability, and is a member of several program committees.

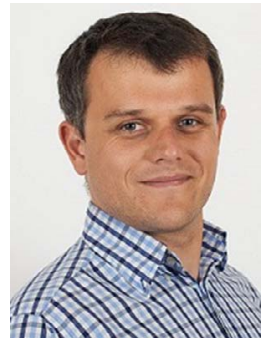

Krzysztof Wnuk is an assistant professor at the Software Engineering Research Group (SERL), Blekinge Institute of Technology, Sweden. His research interests include marketdriven software development, requirements engineering, software product management, decision making in requirements engineering, large-scale software, system and requirements engineering and management and empirica research methods. He is interested in software business, open innovation, and open source software. He works as an expert consultant in software engineering for the Swedish software industry. 